\title{
Econometric Issues in the Analysis of Contagion
}

\author{
Hashem Pesaran and Andreas Pick
}

January 2004

CWPE 0402

Not to be quoted without permission 


\title{
Econometric Issues in the Analysis of Contagion*
}

\author{
M. Hashem Pesaran \\ University of Southern California \& University of Cambridge \\ Andreas Pick \\ University of Cambridge
}

November 2003

\begin{abstract}
This paper presents a canonical, econometric model of contagion and investigates the conditions under which contagion can be distinguished from inter-dependence. In a two-country (market) set up it is shown that for a range of fundamentals the solution is not unique, and for sufficiently large values of the contagion coefficients it has interesting bifurcation properties with bimodal density functions. The extension of the model to herding behaviour is also briefly discussed. To identify contagion effects in the presence of inter-dependencies the equations for the individual markets or countries must contain country (market) specific forcing variables. This sheds doubt on the general validity of the correlation based tests of contagions recently proposed in the literature which do not involve any country (market) specific fundamentals. Finally, we show that ignoring inter-dependence can introduce an upward bias in the estimate of the contagion coefficient, and using Monte Carlo experiments we further show that this bias could be substantial.
\end{abstract}

JEL Classifications: C10, C123, G10, G15

Keywords: Contagion, Inter-dependence, Identification, Financial Crises.

\footnotetext{
${ }^{*}$ We would like to thank Mardi Dungey, Teresa Leitão, Roger Moon, Geert Rider, Til Schuermann and participants at the CERF Seminar, "International Financial Contagion", University of Cambridge, May 2003, and the Econometrics Seminar at the University of Southern California for helpful comments.
} 


\section{Introduction}

Recent episodes of financial crises suggest that they appear in clusters. In the EMS crises in 1992 two countries were forced to leave the exchange rate mechanism and a number of other countries suffered from speculative attacks. In 1994 a number of countries were affected in what came to be known as the "Tequila" crisis. During the Asian crisis in 1997, several Asian economies were struck by severe crises. These episodes have led economists to suggest that financial crises are contagious, that they spread from the originating country to other countries, and that an understanding of the reasons for contagion is essential for forming appropriate economic policies.

The theoretical literature considers a number of reasons for financial crises to appear in clusters. Masson (1999) identifies three categories under which the different theories can be subsumed. First, the theory of "monsoonal effects" suggests that financial crises appear to be contagious because the underlying macroeconomic causes are correlated. Second, financial crises may be transmitted between countries via "spill-overs": a crisis affects another country through external links such as trade. A devaluation in one country exerts pressure on the country's trading partners to devalue. Finally, the theory of "pure contagion" holds that the market jumps from a "good" to a "bad" equilibrium. The jump could be caused by a reversal in a long-standing information cascade. A financial crisis in one country could be considered a signal that, for example, a certain type of economic development strategy is unsustainable. Investors would withdraw their money from countries with apparently similar development strategies and cause a cluster of financial crises.

The first two cases, monsoonal effects and spill-overs, are examples of inter-dependence. Crises resulting from inter-dependence should be largely predictable using macroeconomic fundamentals. If the inter-dependence during non-crises periods is known, the effect of a financial crisis in one country on the likelihood of a crisis in another country can be evaluated. The third case, jumps between equilibria, is what we refer to as contagion in this paper: a largely unpredictable, higher correlation during crises times. This definition of contagion means that a crisis in one country increases the likelihood of a crisis in another country over and above what would be implied by the inter-dependence that prevails between these countries in non-crises times. This definition corresponds to that given by Forbes and Rigobon (2001, 2002).

There are important implications of the distinction between contagion and inter-dependence. Investors need to take a different kind of risk into account for their portfolio choices if markets have a higher correlation after negative shocks. If negative shocks have a much higher correlation across countries than in tranquil times, diversification of portfolios across countries might be less useful than anticipated before a negative shock. 
Economic policy-makers need to be aware of the source of contagion when they are evaluating possible policy responses to a crisis. If the cause of a crisis is a random jump between equilibria, i. e. contagion, international institutional lending to prevent contagion could be a highly effective response as it might return the market to the "good" equilibrium. If, in contrast, a crisis spreads to other countries because their fundamentals are correlated or there are spill-overs affecting the economic fundamentals, international institutional lending cannot prevent the crisis unless it is large enough to change the fundamentals.

There is a large body of empirical research regarding the source of contagion of financial crises, recently reviewed by Dornbusch, Park, and Claessen (2000), Pericoli and Sbracia (2002), and Dungey, Fry, Gonzalez-Hermosillo and Martin (2003). The empirical literature on contagion of currency crises has been largely based on the literature on the macroeconomic causes of currency crises. Using a panel data set, Eichengreen, Rose, and Wyplosz (ERW) (1996) used a pooled probit model to explain a binary indicator of currency crises by a set of macroeconomic variables and a dummy variable for contagion. They found that a crisis elsewhere raises the likelihood of a currency crises by about $8 \%$ and interpreted this finding as an indication of contagion. Similar studies have also been carried out by Esquivel and Larraín (1998), Kruger, Osakwe, and Page (1998), Stone and Weeks (2001), and Kumar, Moorthy, and Perraudin (2002).

Another set of papers examines contagion of financial markets by testing for higher correlation between markets during crises times (King and Wadhwani (1990), Boyer, Gibson, and Loretan (1999), Loretan and English (2000), Forbes and Rigobon (2002) and Corsetti, Pericoli and Sbracia (2002)). Favero and Giavazzi (2002) found significant contagion dummies in their analysis of interest rate spreads in the ERM. Bae, Karolyi and Stulz (2003) test whether the number of contemporaneous extreme stock market returns across a number of markets in a given region can be explained by three common factors, and find that the average exchange rate in the region, the average interest rate in the region, and the conditional volatility of a regional stock market index are significant.

In this paper we propose a canonical model of contagion and provide a solution in the two country (asset) set up. For a range of fundamentals the solution is not unique and for sufficiently large values of the contagion coefficients has interesting bifurcation properties with bimodal density functions. We briefly discuss extensions of this model to cover herding behaviour.

The problem of identification and estimation of the contagion coefficients are discussed and shown to be an example of the general problem of inference in the non-linear simultaneous equation models. To identify contagion effects in the presence of inter-dependencies the equations for the individual markets or countries must contain country (market) specific forcing variables. Therefore, pure correlation-based tests for contagion cannot 
be valid. Country specific fundamentals are needed to distinguish contagion from inter-dependence. The correlation based tests of contagions recently proposed in the literature attempts to overcome the identification problem by assuming that the crises periods can be identified (or known a priori), and that such episodes are sufficiently prolonged and contiguous so that cross-country (market) correlations during crisis and non-crisis periods can be consistently estimated and compared. These are strong assumptions that are unlikely to hold in practice and their implementation tend to be subject to the sample selection bias. Such correlation analyses, by being ex post in nature, are also not very helpful if the focus of the analysis is to develop an early warning system for policy use.

Finally, we show that ignoring the endogeneity of the contagion indicator and/or inter-dependence of the error terms can introduce an upward bias in the estimate of the contagion coefficient, and using Monte Carlo experiments we further show that this bias could be substantial. Our simulations also suggest that the contagion coefficient of 0.54 obtained from pooled probit estimation of ERW's model could be due to neglected inter-dependencies rather than contagion.

\section{A Canonical Model of Contagion: A Two Coun- try Framework}

Consider the following relations

$$
\begin{aligned}
& y_{1 t}=\boldsymbol{\delta}_{1}^{\prime} \mathbf{z}_{t}+\boldsymbol{\alpha}_{1}^{\prime} \mathbf{x}_{1 t}+\beta_{1} \mathrm{I}\left(y_{2 t}-c_{2} \sigma_{2, t-1}\right)+u_{1 t} \\
& y_{2 t}=\boldsymbol{\delta}_{2}^{\prime} \mathbf{z}_{t}+\boldsymbol{\alpha}_{2}^{\prime} \mathbf{x}_{2 t}+\beta_{2} \mathrm{I}\left(y_{1 t}-c_{1} \sigma_{1, t-1}\right)+u_{2 t},
\end{aligned}
$$

where $y_{i t}$ is a performance indicator for country $i=1,2, t=1, \ldots, T$, $u_{1 t}$ and $u_{2 t}$ are serially uncorrelated errors with zero means, conditional variances $\sigma_{u 1, t-1}^{2}$ and $\sigma_{u 2, t-1}^{2}$ and a non-zero correlation coefficient $\rho .^{1}$ The regressors, $\mathbf{x}_{i t}$, are $k_{i} \times 1$ country-specific observed factors assumed to be predetermined and distributed independently of $u_{j t}$ for all $i$ and $j$. Countryspecific dynamics can be allowed for by including $y_{i, t-1}, y_{i, t-2}, \ldots$ in $\mathbf{x}_{i t}$. $\mathbf{z}_{t}$ is an $s \times 1$ vector of pre-determined observed common factors, such as international oil prices, or other common features. $\mathrm{I}(A)$ is an indicator function that takes the value of unity if $A>0$ and zero otherwise

$$
\sigma_{i, t-1}^{2}=\operatorname{Var}\left(y_{i t} \mid \Omega_{t-1}\right),
$$

$\Omega_{t-1}$ is the information available at time $t-1 .^{2}$

\footnotetext{
${ }^{1}$ In the analysis of the solution properties of $y_{1 t}$ and $y_{2 t}$ it is relatively easy to allow for possible time variations in $\rho$. But such a generalisation could obscure the properties of the correlation between $y_{1 t}$ and $y_{2 t}$. As it is shown below $\operatorname{Corr}\left(y_{1 t}, y_{2 t}\right)$ could be time varying even if $\rho$ is fixed.

${ }^{2}$ Note that in general $\sigma_{u i, t-1}^{2} \neq \sigma_{i, t-1}^{2}$.
} 
Examples of performance indicators include stock market returns used by Forbes and Rigobon (2002) and Corsetti, Pericoli and Sbracia (2002), and the index of "exchange market pressure" employed by Eichengreen, Rose and Wylosz (1996) which is a weighted average of exchange rate depreciation, interest rate differential and international reserves ratios. We are assuming that $y_{i t}$ is defined in such a way that a crisis is associated with extreme positive values of $y_{i t}$, and $c_{i}>0$.

In this set up inter-dependence is captured through non-zero values of $\rho$, and is distinguished from contagion effects characterised by non-zero values of $\beta_{i}$.

- It is assumed that contagion takes place only at times of crises, whilst inter-dependence is the result of normal market interactions. ${ }^{3}$

- Country $i$ is said to be in crisis if the performance index, $y_{i t}$ rises above a threshold value $c_{i t}$.

- Contagion is said to occur if a crisis in country 2 increases the probability of a crisis in country 1 over and above the usual market interactions, and vice versa.

- To test for contagion we first need to establish conditions under which the contagion coefficients, $\beta_{i}$ can be identified. Once such conditions are met, a test of contagion in country $i$ can be carried out by testing $\beta_{i}=0$ against the one-sided alternatives, $\beta_{i}>0$.

The above framework can be readily generalised to deal with both extremes simultaneously,

$$
y_{i t}=\boldsymbol{\delta}_{i}^{\prime} \mathbf{z}_{t}+\boldsymbol{\alpha}_{i}^{\prime} \mathbf{x}_{i t}+\beta_{i U} \mathrm{I}\left(y_{j t}-c_{j U} \sigma_{j, t-1}\right)+\beta_{i L} \mathrm{I}\left(-y_{j t}-c_{j L} \sigma_{j, t-1}\right)+u_{i t},
$$

for $i=1,2$, where $\beta_{i U}$ and $\beta_{i L}$ now refer to contagion effects on the upper and the lower tails and $c_{j U} \sigma_{j, t-1}$ and $c_{j L} \sigma_{j, t-1}$ are the associated thresholds with $c_{j U} \geq 0$ and $c_{j L} \geq 0$. It is clear that only one of the indicators can be triggered at a time. In this note we shall focus on the relatively simple case where $\beta_{i L}=0$, but we conjecture that our approach and arguments can be readily extended to the more general case.

\footnotetext{
${ }^{3}$ Such phenomena are also frequently encountered in physics and have been studied extensively in the literature on bifurcation and chaos. For example, in the RayleighBénard convection, heat from the surface of the earth conducts its way to the top of the atmosphere until the rate of heat generation at the surface of the earth gets too high. At this point heat conduction breaks down. The atmosphere develops pairs of convection cells, one rotating left and the other rotating right.
} 


\section{Solution and the Possibility of Multiple Equilib- ria}

Setting

$$
w_{i t}=\boldsymbol{\delta}_{i}^{\prime} \mathbf{z}_{t}+\boldsymbol{\alpha}_{i}^{\prime} \mathbf{x}_{i t}+u_{i t},
$$

we re-write (1) and (2) as

$$
\begin{aligned}
& y_{1 t}=w_{1 t}+\beta_{1} \mathrm{I}\left(y_{2 t}-c_{2}\right), \\
& y_{2 t}=w_{2 t}+\beta_{2} \mathrm{I}\left(y_{1 t}-c_{1}\right),
\end{aligned}
$$

where to simplify the notations and without loss of generality we abstract from the (possibly) time varying nature of the thresholds.

This is a system of non-linear and non-differentiable simultaneous equations and has a simple unique solution when either $\beta_{1}$ or $\beta_{2}$ is zero. For example, suppose that $\beta_{2}=0$. Then the solution is given by

$$
\begin{aligned}
& y_{1 t}=w_{1 t}+\beta_{1} \mathrm{I}\left(y_{2 t}-c_{2}\right), \\
& y_{2 t}=w_{2 t} .
\end{aligned}
$$

When neither of the contagion coefficients is zero the equation system (3) and (4) can be equivalently written as

$$
\begin{aligned}
& Y_{1 t}=W_{1 t}+\mathrm{I}\left(Y_{2 t}\right), \\
& Y_{2 t}=W_{2 t}+\mathrm{I}\left(Y_{1 t}\right),
\end{aligned}
$$

where

$$
Y_{i t}=\frac{y_{i t}-c_{i}}{\beta_{i}}, W_{i t}=\frac{w_{i t}-c_{i}}{\beta_{i}} .
$$

To solve this simplified system we shall consider the following five mutually and exclusive regions in the $\left(W_{1 t}, W_{2 t}\right)$ plane (see also Figure 1 ):

Region A: $W_{2 t}>0$

Region B: $-1<W_{2 t} \leq 0$ and $W_{1 t}>0$,

Region C: $W_{2 t} \leq-1$

Region D: $-1<W_{2 t} \leq 0$ and $W_{1 t}<-1$

Region E: $-1<W_{2 t} \leq 0$ and $-1<W_{1 t} \leq 0$

It is now easily verified that in regions $A$ and $B$, the solution for $Y_{1 t}$ is unique and is given by

$$
Y_{1 t}^{*}=1+W_{1 t}
$$


Figure 1: Regions of $W_{1 t}$ and $W_{2 t}$

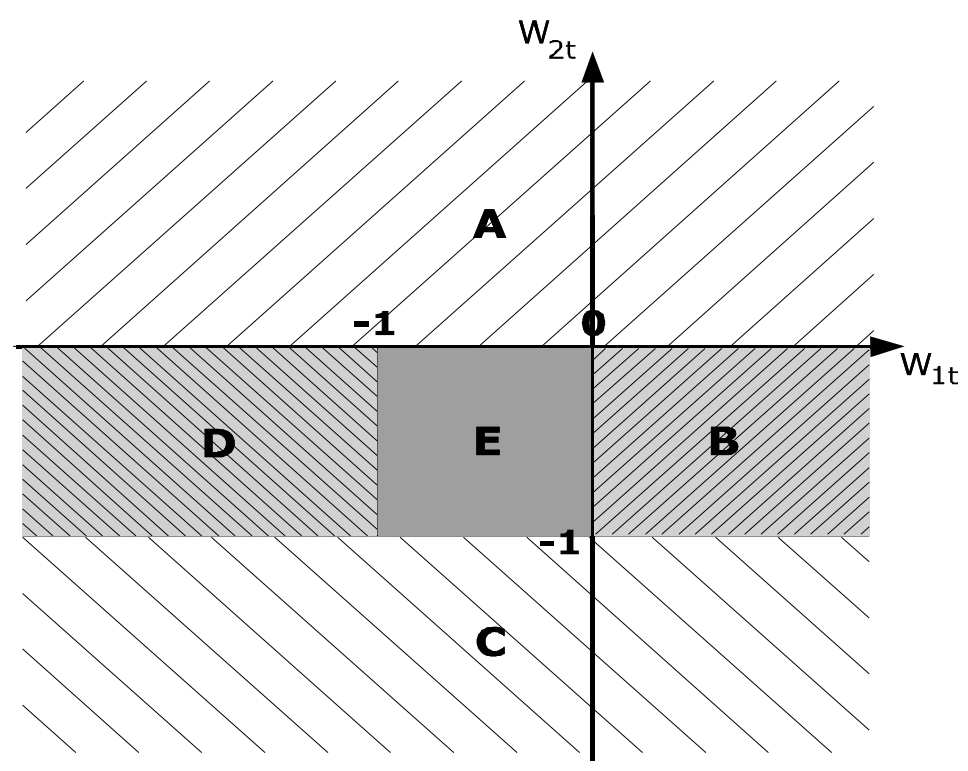

and, similarly, in regions $C$ and $D$ the solution is unique and is given by

$$
Y_{1 t}^{*}=W_{1 t} .
$$

However, in region $E$ the solution is not unique. For example, for $W_{1 t}=$ $-1 / 2$, and $W_{2 t}=-1 / 3$, there are two possible solutions for $\mathbf{Y}_{t}=\left(Y_{1 t}, Y_{2 t}\right)^{\prime}$ given by

$$
\mathbf{Y}_{t}^{a}=\left(\begin{array}{c}
-1 / 2 \\
-1 / 3
\end{array}\right) \text { and } \mathbf{Y}_{t}^{b}=\left(\begin{array}{c}
1 / 2 \\
2 / 3
\end{array}\right)
$$

Using the index $d_{t}$ to designate the choice of the solution when $-1<W_{i t} \leq 0$ we have

$$
Y_{i t}^{*}\left(d_{t}\right)=d_{t} W_{i t}+\left(1-d_{t}\right)\left(1+W_{i t}\right), \text { for } i=1,2,
$$

where the "favourable" solution occurs if $d_{t}=1$, and the "unfavourable" solution occurs if $d_{t}=0$. Notice that in the present set up the crisis (unfavourable outcome) is associated with the upper tail (large positive values). It is clear from Equation (12) that the distribution of $Y_{i t}^{*}\left(d_{t}\right)$ is a mean mixture of distributions with $d_{t}$ as the selection parameter. Hence, $d_{t} \sim \operatorname{Bernoulli}(\pi)$, where $\pi$ is the probability of $W_{i t}$ being chosen in the mixture.

This is an interesting example where non-uniqueness arises only if the fundamentals (as measured by $W_{i t}$ ) for both countries (markets) are favourable but weak (in relation to the threshold values). This appears similar to the 
notion of weak fundamentals used by Sachs, Tornell and Velasco (1996). This result also raises the possibility of policy intervention for ensuring that the "favourable" solution is in fact selected. It is also reasonable to expect that the correlation of $Y_{1 t}$ and $Y_{2 t}$ would be higher if the unfavourable solution is chosen as compared to the favourable one. Simulation results reported below bear this out.

Collecting the various components of the solution given by (10) to (12) we have

$$
\begin{aligned}
& Y_{1 t}=\left(1+W_{1 t}\right) \mathrm{I}\left(W_{2 t}\right) \\
& +\left(1+W_{1 t}\right) \mathrm{I}\left(-W_{2 t}\right) \mathrm{I}\left(1+W_{2 t}\right) \mathrm{I}\left(W_{1 t}\right) \quad \text { (Region B) } \\
& +W_{1 t} \mathrm{I}\left(-1-W_{2 t}\right) \quad \text { (Region } \mathrm{C} \text { ) } \\
& +W_{1 t} \mathrm{I}\left(-W_{2 t}\right) \mathrm{I}\left(1+W_{2 t}\right) \mathrm{I}\left(-1-W_{1 t}\right) \quad(\text { Region } \mathrm{D}) \\
& \left.+Y_{1 t}^{*}\left(d_{t}\right) \mathrm{I}\left(-W_{2 t}\right) \mathrm{I}\left(1+W_{2 t}\right) \quad \text { (Region } \mathrm{E}\right) \\
& \times \mathrm{I}\left(-W_{1 t}\right) \mathrm{I}\left(1+W_{1 t}\right)
\end{aligned}
$$

and by symmetry

$$
\begin{aligned}
Y_{2 t}= & \left(1+W_{2 t}\right) \mathrm{I}\left(W_{1 t}\right) \\
& +\left(1+W_{2 t}\right) \mathrm{I}\left(-W_{1 t}\right) \mathrm{I}\left(1+W_{1 t}\right) I\left(W_{2 t}\right) \\
& +W_{2 t} \mathrm{I}\left(-1-W_{1 t}\right) \\
& +W_{2 t} \mathrm{I}\left(-W_{1 t}\right) \mathrm{I}\left(1+W_{1 t}\right) \mathrm{I}\left(-1-W_{2 t}\right) \\
& +Y_{2 t}^{*}\left(d_{t}\right) \mathrm{I}\left(-W_{1 t}\right) \mathrm{I}\left(1+W_{1 t}\right) \mathrm{I}\left(-W_{2 t}\right) \mathrm{I}\left(1+W_{2 t}\right) .
\end{aligned}
$$

In terms of the original variables we obtain

$$
y_{i t}^{*}=\beta_{i} Y_{i t}^{*}+c_{i t}, \text { for } i=1,2 .
$$

It is important that the above solution is valid even if $y_{i, t-1}, y_{i, t-2}$, are included amongst of the individual-specific regressors, $\mathbf{x}_{i t}$. This feature considerably enhance the relevance of the model to the analysis of financial markets that show a mild degree of short term over-shooting.

It is clear that $y_{1 t}$ and $y_{2 t}$ will be correlated even if $w_{1 t}$ and $w_{2 t}$ are independently distributed, i.e. for values of $\beta_{i}>0, \operatorname{Corr}\left(y_{1 t}, y_{2 t}\right)>0$ even when $\operatorname{Corr}\left(w_{1 t}, w_{2 t}\right)=0$. For example, consider the simple case where $\beta_{2}=0$ and $\beta_{1}>0$ of Equations (5) and (6) and $w_{1 t}, w_{2 t}$ are independently distributed. In this case

$$
\operatorname{Cov}\left(y_{1 t}, y_{2 t}\right)=\beta_{1}\left[1-\mathrm{F}_{2}\left(c_{2 t}\right)\right]\left\{\mathrm{E}\left(w_{2 t}-c_{2 t} \mid w_{2 t}>c_{2 t}\right)-\mathrm{E}\left(w_{2 t}-c_{2 t}\right)\right\},
$$

and

$$
\operatorname{Corr}\left(y_{1 t}, y_{2 t}\right)=\frac{\beta_{1}\left[1-\mathrm{F}_{2}\left(c_{2 t}\right)\right]\left\{\mathrm{E}\left(w_{2 t}-c_{2 t} \mid w_{2 t}>c_{2 t}\right)-\mathrm{E}\left(w_{2 t}-c_{2 t}\right)\right\}}{\sqrt{\operatorname{Var}\left(w_{2 t}\right)\left\{\operatorname{Var}\left(w_{1 t}\right)+\beta_{1}^{2} \mathrm{~F}_{2}\left(c_{2 t}\right)\left[1-\mathrm{F}_{2}\left(c_{2 t}\right)\right]\right\}}},
$$


where $\mathrm{F}_{2}(x)$ is the cumulative distribution function of $w_{2 t}$. In the extreme value literature, $\mathrm{E}\left(w_{2 t}-c_{2 t} \mid w_{2 t}>c_{2 t}\right)$ is known as the mean excess function of $w_{2 t}$, see for example Embrechts, Klüppelberg and Mikosch (1997). This result provide support for the hypothesis that the degree of the dependence of $y_{1 t}$ and $y_{2 t}$ is an increasing function of the degree of the fattailedness of the $w_{2 t}$ process. For $w_{i t} \sim \mathrm{N}(0,1)$,

$\operatorname{Corr}\left(y_{1 t}, y_{2 t}\right)=\frac{\beta_{1}\left[1-\Phi\left(c_{2 t}\right)\right]\left\{\mathrm{E}\left(w_{2 t} \mid w_{2 t}>c_{2 t}\right)\right\}}{\sqrt{1+\beta_{1}^{2} \Phi\left(c_{2 t}\right)\left[1-\Phi\left(c_{2 t}\right)\right]}}>0$, for $\beta_{1}>0, c_{2 t}>0$.

\section{Some Numerical Results}

Suppose that $c_{i t}=1.64$ (that corresponds to the upper $95 \%$ tail of the standard normal), let $\beta_{1}=\beta_{2}=\beta$, and

$$
\left(\begin{array}{l}
w_{1 t} \\
w_{2 t}
\end{array}\right) \sim \mathrm{N}\left(\mathbf{0},\left(\begin{array}{cc}
1 & \rho \\
\rho & 1
\end{array}\right)\right) .
$$

Using these parameters we can sample the dependent variables and investigate their properties for different values of the contagion coefficient $\beta$. The results reported below are based on 30,000 sampled values of $y_{1 t}$ and $y_{2 t}$.

Table 1 reports the moments of $y_{1 t}$ and the correlation of $y_{1 t}$ and $y_{2 t}$ under the assumption that only one of the mixture distributions is visited, note however that due to the symmetry of the model the reported moments also apply to $y_{2 t}$. On the left side of the table the results for $\pi=1$ are reported and on the right side the results for $\pi=0$.

Table 1: Moments of the distribution of $\mathbf{y}_{t}$

\begin{tabular}{|c|c|c|c|c|c|c|c|c|}
\hline \multirow[b]{2}{*}{$\beta$} & \multicolumn{4}{|c|}{$\pi=1\left(d_{t}=1\right)$} & \multicolumn{4}{|c|}{$\bar{\pi} \pi=0 \quad\left(d_{t}=0\right)$} \\
\hline & $\bar{y}_{1}$ & $\sigma\left(y_{1}\right)$ & Kurt & Corr & $\bar{y}_{1}$ & $\sigma\left(y_{1}\right)$ & Kurt & Corr \\
\hline & \multicolumn{8}{|c|}{$\rho=0$} \\
\hline 0.5 & 0.028 & 1.00 & 0.08 & 0.120 & 0.030 & 1.01 & 0.07 & 0.127 \\
\hline 1.0 & 0.063 & 1.05 & 0.43 & 0.238 & 0.107 & 1.11 & 0.15 & 0.319 \\
\hline 2.0 & 0.161 & 1.24 & 1.96 & 0.457 & 0.863 & 1.69 & -1.13 & 0.706 \\
\hline & \multicolumn{8}{|c|}{$\rho=0.5$} \\
\hline 0.5 & 0.065 & 1.48 & 0.06 & 0.602 & 0.071 & 1.49 & 0.03 & 0.606 \\
\hline 1.0 & 0.154 & 1.61 & 0.15 & 0.677 & 0.212 & 1.66 & -0.15 & 0.697 \\
\hline 2.0 & 0.369 & 1.94 & 0.19 & 0.767 & 0.907 & 2.18 & -1.05 & 0.816 \\
\hline
\end{tabular}

"Kurt" denotes Kurtosis-3 of the distribution of $y_{1 t}$ and "Corr" the correlation between $y_{1 t}$ and $y_{2 t}$.

Rather than choosing only one part of the mixture in (15) one can also consider intermediate cases where both parts of the mixture are visited. Below we set $\pi=0.5$ by sampling $d_{t}=\mathrm{I}\left(s_{t}\right)$ where $s_{t}$ is the realisation of 
a random variable characterising the nature of the policy intervention. In a purely random case where $s_{t} \sim \mathrm{N}(0,1)$ one obtains very pronounced bimodal distributions for $y_{i t}^{*}$. A clear polar separation of solutions emerge when $\beta$ is large, as can be seen in Figures 2-3 for $\beta=2$ and $\rho=0.8$. More dramatic pictures can be obtained for larger values of $\beta$ as in Figure 4 and 5. These parameter values are chosen for illustrative purposes and we do not expect to observe such extreme phenomena in practice. For small values of $\beta$ the polarisation is very slight and cannot be revealed by visual inspection. This can be seen in Figures 6 and 7, which display the results for $\beta=0.5$ and $\rho=0.5$. 


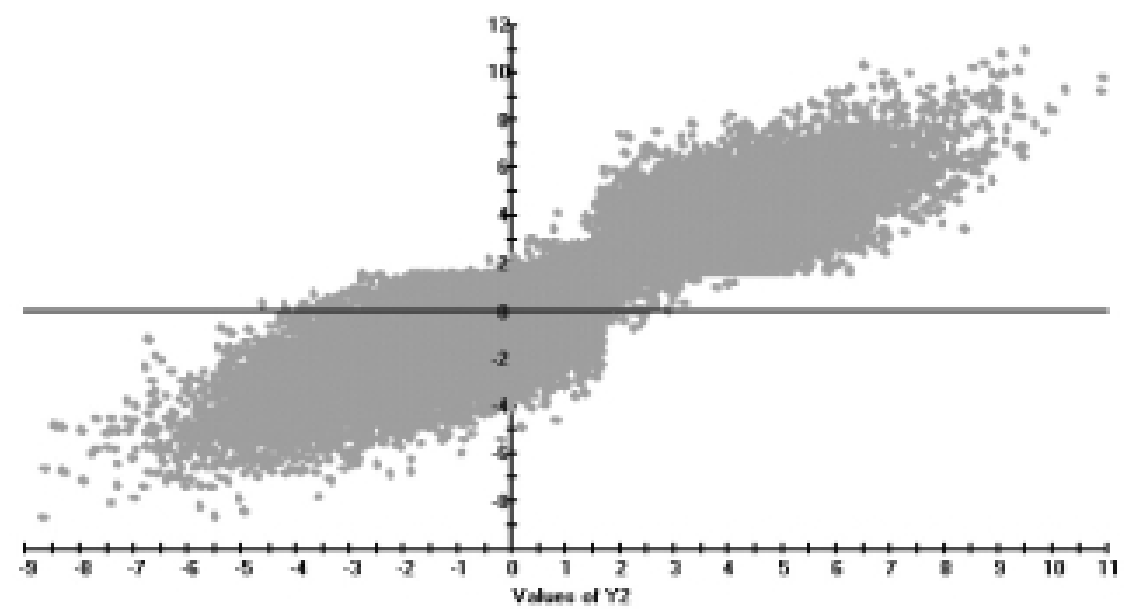

Figure 2: Scatter plot of $y_{1}$ on $y_{2}(\beta=2, \rho=0.8, \pi=0.5)$

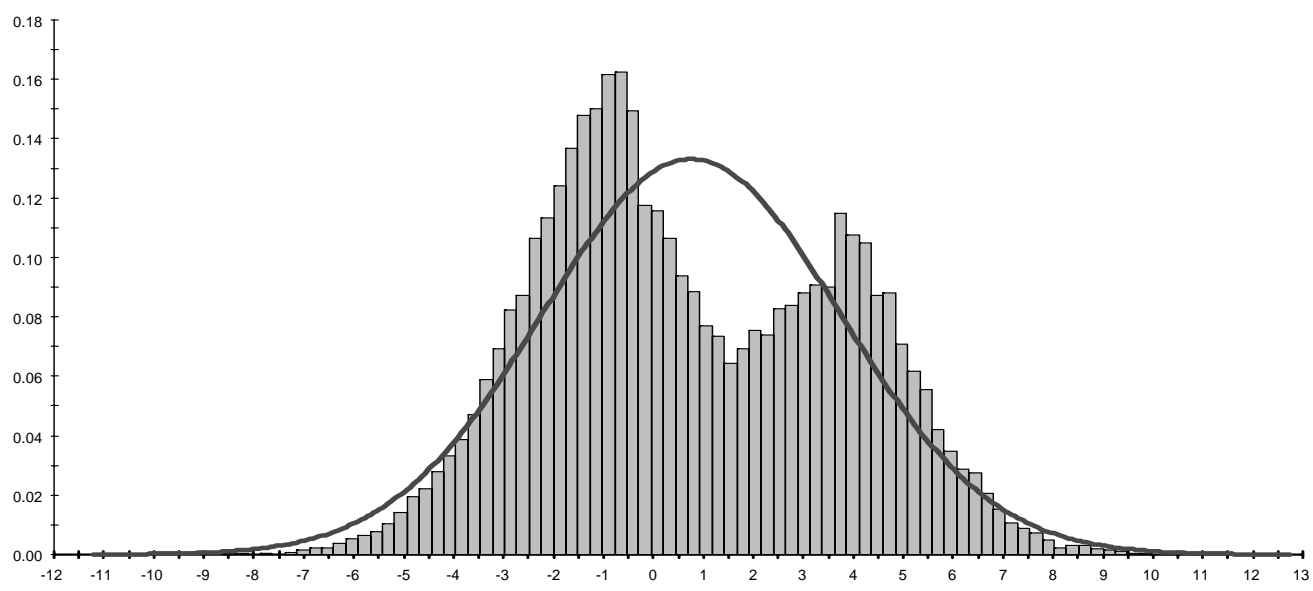

Figure 3: Histogram and normal curve for $y_{1}(\beta=2, \rho=0.8, \pi=0.5)$ 


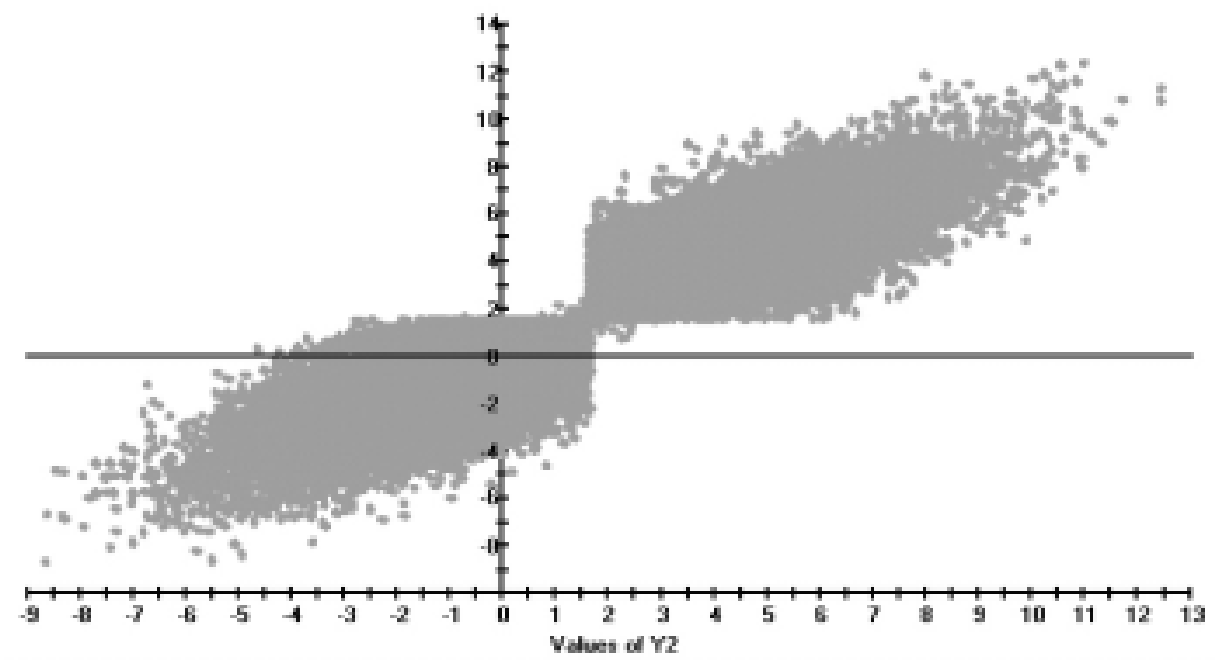

Figure 4: Scatter plot of $y_{1}$ on $y_{2}(\beta=3.5, \rho=0.8, \pi=0.5)$

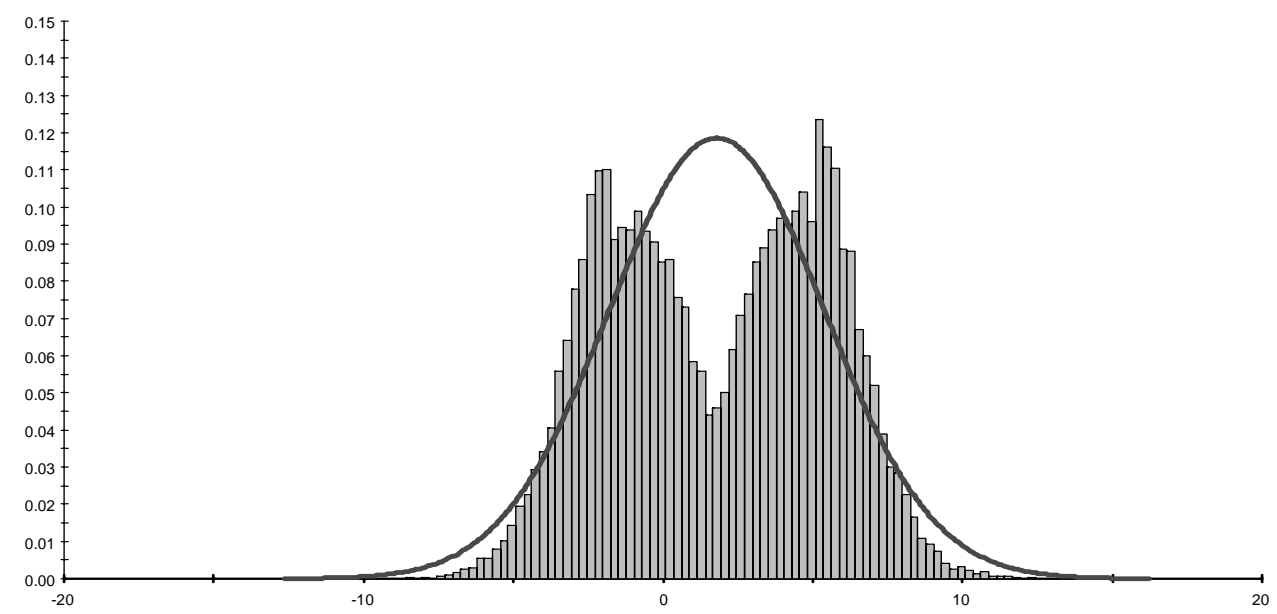

Figure 5: Histogram and normal curve for $y_{1}(\beta=3.5, \rho=0.8, \pi=0.5)$ 


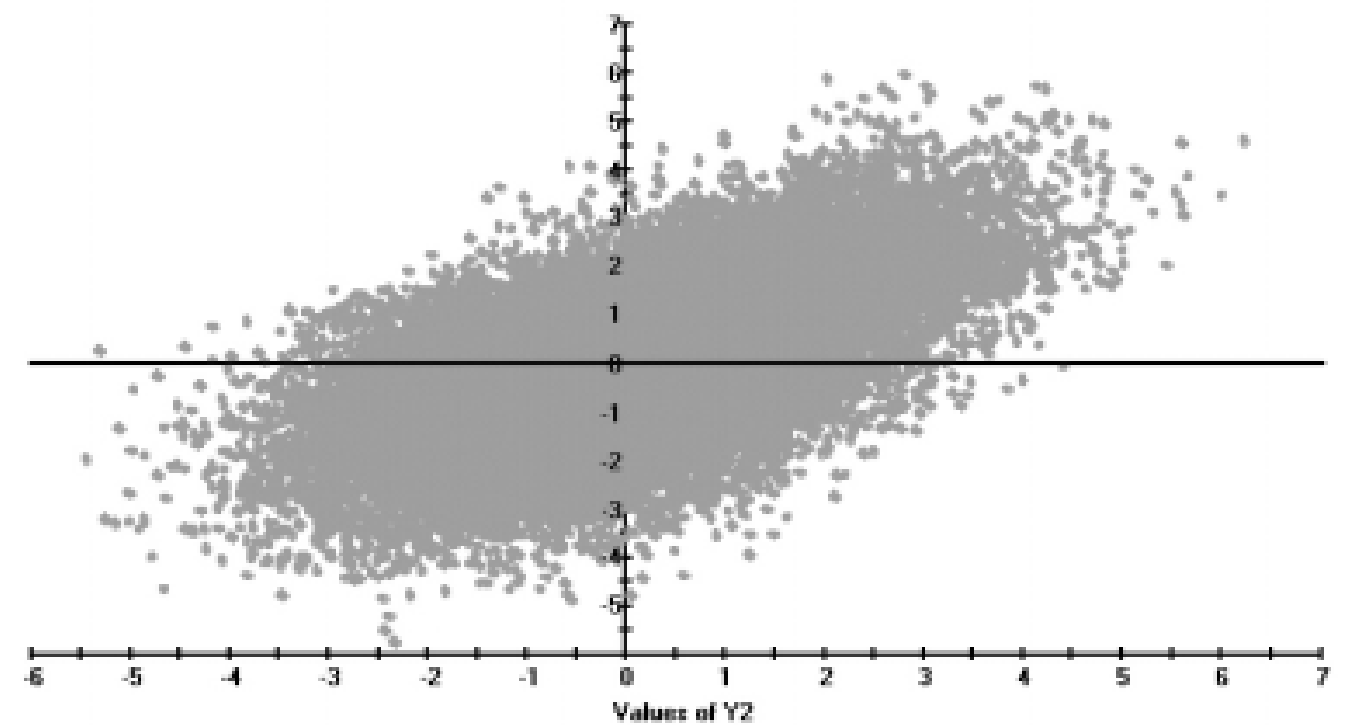

Figure 6: Scatter plot of $y_{1}$ on $y_{2}(\beta=0.5, \rho=0.8, \pi=0.5)$

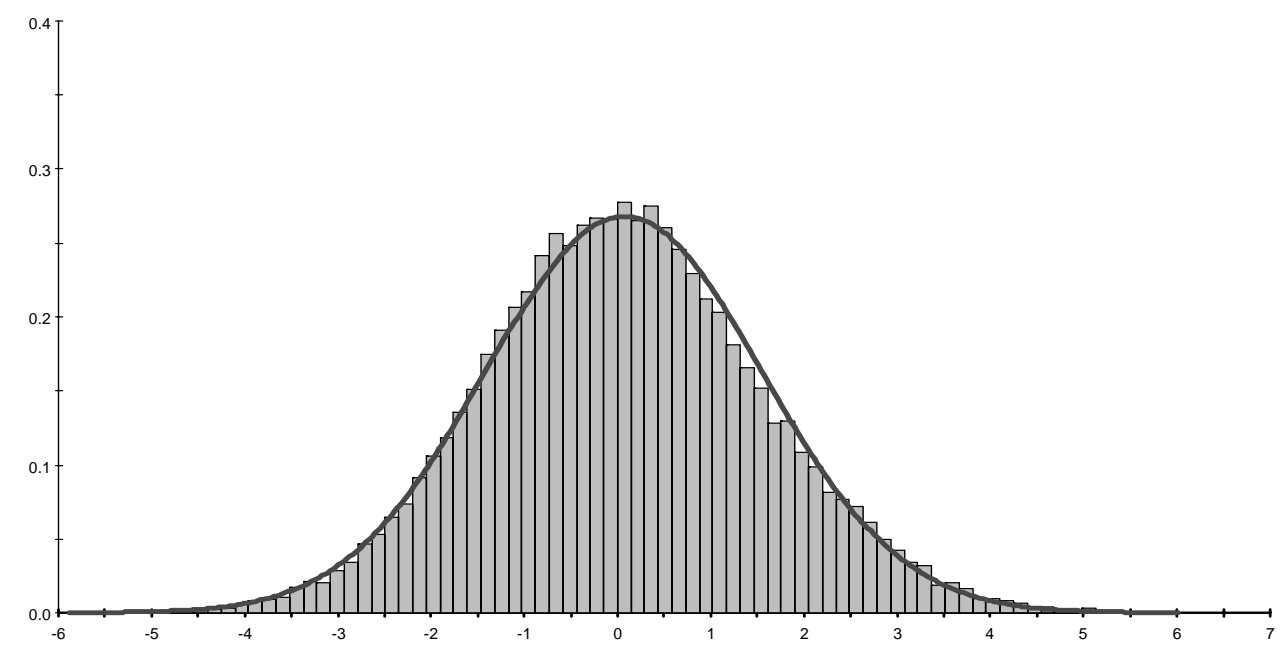

Figure 7: Histogram and normal curve for $y_{1}(\beta=0.5, \rho=0.8, \pi=0.5)$ 


\section{$5 \quad$ Herding and Contagion}

The literature on herding places important emphasis on the discounting of private (or individual-specific) information at times of crisis. Combining a herding effect with contagion the system of equations (1) and (2) can be generalised as

$$
\begin{aligned}
& y_{1 t}=\boldsymbol{\delta}_{1}^{\prime} \mathbf{z}_{t}+\boldsymbol{\alpha}_{1}^{\prime} \mathbf{x}_{1 t}\left[1-\varphi_{1} \mathrm{I}\left(y_{2 t}-c_{2} \sigma_{2, t-1}\right)\right]+\beta_{1} \mathrm{I}\left(y_{2 t}-c_{2} \sigma_{2, t-1}\right)+u_{1 t}, \\
& y_{2 t}=\boldsymbol{\delta}_{2}^{\prime} \mathbf{z}_{t}+\boldsymbol{\alpha}_{2}^{\prime} \mathbf{x}_{2 t}\left[1-\varphi_{2} \mathrm{I}\left(y_{1 t}-c_{1} \sigma_{1, t-1}\right)\right]+\beta_{2} \mathrm{I}\left(y_{1 t}-c_{1} \sigma_{1, t-1}\right)+u_{2 t},
\end{aligned}
$$

where $\varphi_{i}$ can be viewed as a herding coefficient if the individual-specific variables $\mathbf{x}_{1 t}$ and $\mathbf{x}_{2 t}$ are independently distributed. It would be reasonable to expect that $1 \geq \varphi_{i} \geq 0$, so that herding has a discounting, non-perverse effect on private information. In the case where $\mathbf{x}_{1 t}$ and $\mathbf{x}_{2 t}$ are correlated, the "herding factors", $-\varphi_{i} \mathrm{I}\left(y_{j t}-c_{j} \sigma_{j, t-1}\right) i, j=1,2$, must be applied to the non-correlated components of $\mathbf{x}_{1 t}$ and $\mathbf{x}_{2 t}$. Under this set up private information is discounted only in crisis periods. Dynamics can be introduced in the model by allowing $\mathbf{x}_{i t}$ to contain lagged values, $y_{i, t-1}, y_{i, t-2}, \ldots$.

The model might also be written as

$$
y_{i t}=\boldsymbol{\delta}_{i}^{\prime} \mathbf{z}_{t}+\boldsymbol{\alpha}_{i}^{\prime} \mathbf{x}_{i t}+\left[\beta_{i}-\varphi_{i} \boldsymbol{\alpha}_{i}^{\prime} \mathbf{x}_{i t}\right] \mathrm{I}\left(y_{j t}-c_{j} \sigma_{j, t-1}\right)+u_{i t}, \text { for } i, j=1,2,
$$

and solved/analysed as before by treating $\beta_{i}$ in the previous set up as a time varying coefficient, $\beta_{i t}=\beta_{i}-\varphi_{i} \boldsymbol{\alpha}_{i}^{\prime} \mathbf{x}_{i t}$. In the case where $\mathbf{x}_{1 t}$ and $\mathbf{x}_{2 t}$ are independently distributed it is easy to show that the covariance of $y_{1 t}$ and $y_{2 t}$ does not increase as a result of herding, so long as contagion effects are not operating $\left(\beta_{i}=0\right)$. In fact herding (as defined here) reduces correlations as it raises volatilities without increasing covariances. This is in contrast to the case of contagion which is generally associated with a rise in correlations. Therefore, there is some potential in joint consideration of herding and contagion. But a detailed discussion would be beyond the scope of the present paper.

\section{Identification and Estimation of the Contagion Coefficients}

The system of equations (1) and (2) represent a two-equation non-linear simultaneous equation model which has been studied extensively in the econometric literature as summarised by Amemiya (1985), for example. The above equation systems whilst non-linear in the endogenous variables, $\mathbf{y}_{t}=\left(y_{1 t}, y_{2 t}\right)^{\prime}$, are linear in the parameters for known threshold values, $c_{1}$ and $c_{2}$. This somewhat simplifies the identification and estimation problems. In what follows we focus on this relatively simple case by assuming that $c_{1}$ and $c_{2}$ are known and that the variances $\sigma_{i, t-1}$ are time invariant and can 
be absorbed in $c_{i}$. The non-uniqueness of the solution is not by itself an impediment to identification and/or consistent estimation of the unknown parameters. However, efficient estimation of the parameters, for example by the maximum likelihood method, requires that the solutions (13) and (14) are augmented with an additional process that specifies the distribution of $d_{t}$, the solution indicator. As in the case of simultaneous equation models, it is possible to consistently estimate the parameters of a single equation in a system without necessarily having to fully specify the system of equations. An additional equation for $d_{t}$, is not essential for the consistent estimation of the contagion coefficients $\beta_{i}$, for example. But the identification problem becomes much more complicated and poses new challenges if the focus of the analysis is also on the identification of the $d_{t}$ process itself. The resolution of this problem poses new challenges and is beyond the scope of the present paper. Hence, our focus will be on identification and consistent estimation of the contagion coefficients.

\subsection{Inconsistency of the OLS Estimators}

Consider the Ordinary Least Squares (OLS) regressions of $y_{i t}$ on $\mathbf{z}_{t}, \mathbf{x}_{i, t}$, $\mathrm{I}\left(y_{j t}-c_{j}\right)$, for $i, j=1,2$ and for simplicity suppose that the two equations only contain one country-specific regressor each and assume that these regressors $\left(x_{1 t}, x_{2}\right)$ are strictly exogenous and stationary, distributed independently of the errors, $u_{1 t}$ and $u_{2 t}$ :

$$
\begin{aligned}
& y_{1 t}=\alpha_{1} x_{1 t}+\beta_{1} \mathrm{I}\left(y_{2 t}-c_{2}\right)+u_{1 t}, \\
& y_{2 t}=\alpha_{2} x_{2 t}+\beta_{2} \mathrm{I}\left(y_{1 t}-c_{1}\right)+u_{2 t},
\end{aligned}
$$

where

$$
\left(\begin{array}{l}
u_{1 t} \\
u_{2 t}
\end{array}\right) \mid x_{1 t}, x_{2 t} \sim N\left[\left(\begin{array}{l}
0 \\
0
\end{array}\right),\left(\begin{array}{cc}
\sigma_{u 1}^{2} & \rho \sigma_{u 1} \sigma_{u 2} \\
\rho \sigma_{u 1} \sigma_{u 2} & \sigma_{u 2}^{2}
\end{array}\right)\right]
$$

Suppose also that probability of crisis occurring in either of the two countries are neither zero nor unity, namely ${ }^{4}$

$$
T^{-1} \sum_{t=1}^{T} \mathrm{I}\left(y_{j t}-c_{j}\right) \rightarrow \pi_{j}, \text { where } 1>\pi_{j}>0 .
$$

\footnotetext{
${ }^{4}$ This is not a primitive assumption and is made here for convenience. The crisis probabilities, $\pi_{j}, j=1,2$ depend in a complicated manner on the parameters of the model and the probability distribution functions of the forcing variables, $x_{j t}$, and the disturbances, $u_{j t}$, for $j=1,2$. These probabilities can be computed numerically using the solutions given by (13) and (14).
} 
We also have

$$
\begin{aligned}
T^{-1} \sum_{t=1}^{T} x_{j t}^{2} & \rightarrow \sigma_{x j}^{2}>0, \\
T^{-1} \sum_{t=1}^{T} x_{j t} u_{i t} & \rightarrow 0, \text { for } i, j=1,2 .
\end{aligned}
$$

The OLS estimator of $\beta_{1}$ is given by

$$
\hat{\beta}_{1}=\left(\mathbf{d}_{2}^{\prime} \mathbf{M}_{1} \mathbf{d}_{2}\right)^{-1} \mathbf{d}_{2}^{\prime} \mathbf{M}_{1} \mathbf{y}_{1},
$$

where $\mathbf{d}_{2}=\left(\mathrm{I}\left(y_{21}-c_{2}\right), \mathrm{I}\left(y_{22}-c_{2}\right), \ldots, \mathrm{I}\left(y_{2 T}-c_{2}\right)\right)^{\prime}, \mathbf{M}_{1}=\mathbf{I}_{T}-\mathbf{x}_{1}\left(\mathbf{x}_{1}^{\prime} \mathbf{x}_{1}\right)^{-1} \mathbf{x}_{1}^{\prime}$, $\mathbf{x}_{1}=\left(x_{11}, x_{12}, \ldots, x_{1 T}\right)^{\prime}$, and $\mathbf{y}_{1}=\left(y_{11}, y_{12}, \ldots, y_{1 T}\right)^{\prime}$. But

$$
T^{-1}\left(\mathbf{d}_{2}^{\prime} \mathbf{M}_{1} \mathbf{d}_{2}\right)=T^{-1} \sum_{t=1}^{T} \mathrm{I}\left(y_{2 t}-c_{2}\right)-\frac{\left[T^{-1} \sum_{t=1}^{T} \mathrm{I}\left(y_{2 t}-c_{2}\right) x_{1 t}\right]^{2}}{T^{-1} \sum_{t=1}^{T} x_{1 t}^{2}},
$$

and $T^{-1}\left(\mathbf{d}_{2}^{\prime} \mathbf{M}_{1} \mathbf{d}_{2}\right)$ tends to a non-zero constant, $\omega_{22}>0$. This is easily seen in the simple case where $x_{1 t}=1$ for all $t$. In this case $T^{-1}\left(\mathbf{d}_{2}^{\prime} \mathbf{M}_{1} \mathbf{d}_{2}\right)$ converges to $\pi_{2}\left(1-\pi_{2}\right)>0$. Hence

$$
\operatorname{plim}_{T \rightarrow \infty}\left(\hat{\beta}_{1}\right)=\beta_{1}+\frac{\operatorname{plim}_{T \rightarrow \infty}\left(\frac{\mathbf{d}_{2}^{\prime} \mathbf{M}_{1} \mathbf{u}_{1}}{T}\right)}{\omega_{22}} .
$$

where $\mathbf{u}_{1}=\left(u_{11}, u_{12}, \ldots, u_{1 T}\right)^{\prime}$. Also under our assumptions (see in particular (19) and (20))

$$
\begin{aligned}
\operatorname{plim}_{T \rightarrow \infty}\left(\frac{\mathbf{d}_{2}^{\prime} \mathbf{M}_{1} \mathbf{u}_{1}}{T}\right) & =\operatorname{plim}_{T \rightarrow \infty}\left(\frac{\mathbf{d}_{2}^{\prime} \mathbf{u}_{1}}{T}\right)-\frac{\operatorname{plim}_{T \rightarrow \infty}\left(\frac{\mathbf{d}_{2}^{\prime} \mathbf{x}_{1}}{T}\right) \operatorname{plim}_{T \rightarrow \infty}\left(\frac{\mathbf{x}_{1}^{\prime} \mathbf{u}_{1}}{T}\right)}{\sigma_{x 1}^{2}} \\
& =\mathrm{E}\left[u_{1 t} \mathrm{I}\left(y_{2 t}-c_{2}\right)\right],
\end{aligned}
$$

and

$$
\operatorname{plim}_{T \rightarrow \infty}\left(\hat{\beta}_{1}\right)=\beta_{1}+\frac{\mathrm{E}\left[u_{1 t} \mathrm{I}\left(y_{2 t}-c_{2}\right)\right]}{\omega_{22}} .
$$

In general, $\mathrm{E}\left[u_{1 t} \mathrm{I}\left(y_{2 t}-c_{2}\right)\right] \neq 0$, and the OLS estimator of $\beta_{1}$ is inconsistent. The sign and the magnitude of the inconsistency of $\hat{\beta}_{1}$ depends on $\beta_{2}$ and $\rho$. The OLS estimator of $\beta_{1}$ is consistent only if $\beta_{2}=\rho=0$, namely if the contagion model is recursive (trinagular) and there are no interdependencies through the errors. To see this consider the relatively simple case where $\beta_{2}=0$, and note that under normally distributed errors we have

$$
u_{1 t}=\rho\left(\frac{\sigma_{u 1}}{\sigma_{u 2}}\right) u_{2 t}+v_{t}
$$


where $u_{2 t}$ and $v_{t}$ are independently distributed. Note also that $v_{t}$ is distributed independently of $x_{1 t}$ and $x_{2 t}$ and has a zero mean. In this case

$$
\begin{aligned}
\mathrm{E}\left[u_{1 t} \mathrm{I}\left(y_{2 t}-c_{2}\right)\right] & =\mathrm{E}\left[u_{1 t} \mathrm{I}\left(\alpha_{2} x_{2 t}+u_{2 t}-c_{2}\right)\right] \\
& =\rho\left(\frac{\sigma_{u 1}}{\sigma_{u 2}}\right) \mathrm{E}\left[u_{2 t} \mathrm{I}\left(\alpha_{2} x_{2 t}+u_{2 t}-c_{2}\right)\right]+\mathrm{E}\left[v_{t} \mathrm{I}\left(\alpha_{2} x_{2 t}+u_{2 t}-c_{2}\right)\right]
\end{aligned}
$$

Since $v_{t}$ is distributed independently of $x_{2 t}$ and $u_{2 t}$, then conditional on $x_{2 t}$ and $u_{2 t}$

$$
\mathrm{E}\left[v_{t} \mathrm{I}\left(\alpha_{2} x_{2 t}+u_{2 t}-c_{2}\right) \mid u_{2 t}, x_{2 t}\right]=\mathrm{I}\left(\alpha_{2} x_{2 t}+u_{2 t}-c_{2}\right) \mathrm{E}\left(v_{t} \mid u_{2 t}, x_{2 t}\right)=0,
$$

and

$$
\mathrm{E}\left[u_{1 t} \mathrm{I}\left(y_{2 t}-c_{2}\right)\right]=\rho\left(\frac{\sigma_{u 1}}{\sigma_{u 2}}\right) \mathrm{E}\left[u_{2 t} \mathrm{I}\left(\alpha_{2} x_{2 t}+u_{2 t}-c_{2}\right)\right] .
$$

The following lemma shows that when $\rho>0$, and $\beta_{2}=0$, then $\mathrm{E}\left[u_{2 t} \mathrm{I}\left(y_{2 t}-\right.\right.$ $\left.\left.c_{2}\right)\right]>0$, and $\hat{\beta}_{1}$ will be a consistent estimator of $\beta_{1}$ if and only if $\rho=0$. The direction of the bias is upward when $\rho>0$, and downward if $\rho<0$.

Lemma 1 Suppose $\beta_{2}=0$, and conditional on $x_{2 t}$, $u_{2 t}$ is normally distributed, then $\mathrm{E}\left[u_{2 t} \mathrm{I}\left(y_{2 t}-c_{2}\right)\right]>0$ if $\rho>0$.

Proof. Under $\beta_{2}=0, u_{2 t} \mathrm{I}\left(y_{2 t}-c_{2}\right)=u_{2 t} \mathrm{I}\left(\alpha_{2} x_{2 t}+u_{2 t}-c_{2}\right)=u_{2 t}^{*}$, where

$$
u_{2 t}^{*}= \begin{cases}u_{2 t} & \text { if } u_{2 t}>c_{2}-\alpha_{2} x_{2 t} \\ 0 & \text { otherwise }\end{cases}
$$

Conditional on $x_{2 t}$, noting that by assumption $x_{2 t}$, and $u_{2 t}$ are independently distributed we have,

$$
\mathrm{E}\left(u_{2 t}^{*} \mid x_{2 t}\right)=\operatorname{Pr}\left(u_{2 t}>c_{2}-\alpha x_{2 t} \mid x_{2 t}\right) \mathrm{E}\left(u_{2 t} \mid u_{2 t}>c_{2}-\alpha_{2} x_{2 t}, x_{2 t}\right) .
$$

But

$$
\mathrm{E}\left(u_{2 t} \mid u_{2 t}>c_{2}-\alpha_{2} x_{2 t}, x_{2 t}\right)=\frac{\sigma_{u 2} \phi\left(\frac{c_{2}-\alpha_{2} x_{2 t}}{\sigma_{u 2}}\right)}{\operatorname{Pr}\left(u_{2 t}>c_{2}-\alpha_{2} x_{2 t}, x_{2 t}\right)} .
$$

and hence

$$
\mathrm{E}\left(u_{2 t}^{*} \mid x_{2 t}\right)=\sigma_{u 2} \phi\left(\frac{c_{2}-\alpha_{2} x_{2 t}}{\sigma_{u 2}}\right)
$$

Since $\phi\left(\frac{c_{2}-\alpha_{2} x_{2 t}}{\sigma_{u 2}}\right)>0$ for all values of $x_{2 t}$, we also have:

$$
\mathrm{E}\left(u_{2 t}^{*}\right)=\mathrm{E}\left[u_{2 t} \mathrm{I}\left(y_{2 t}-c_{2}\right)\right]>0 .
$$


Consider now the general case where $\rho>0$ and $\beta_{2}>0$, and note that in this case (using (21)) we have

$$
\mathrm{E}\left[u_{1 t} \mathrm{I}\left(y_{2 t}-c_{2}\right)\right]=\rho\left(\frac{\sigma_{u 1}}{\sigma_{u 2}}\right) \mathrm{E}\left[u_{2 t} \mathrm{I}\left(Y_{2 t}\right)\right]+\mathrm{E}\left[\varepsilon_{1 t} \mathrm{I}\left(Y_{2 t}\right)\right],
$$

where $Y_{2 t}$ is given by the solution (14), which takes either the value of $W_{2 t}$ or $1+W_{2 t}$. The probability of whether the solution is $W_{2 t}$ or $1+W_{2 t}$ depends, in a complicated manner, on the probability of $W_{1 t}$ and $W_{2 t}$ falling in the regions $\mathrm{A}, \mathrm{B}, \mathrm{C}, \mathrm{D}$, and $\mathrm{E}$, and the probability of a particular solution being selected if $W_{1 t}$ and $W_{2 t}$ fall in region $\mathrm{E}$. In the Appendix we give results from Monte Carlo experiments, which show that the expectation is positive for a wide range of values of $\beta_{1}, \beta_{2}, \alpha_{1}, \alpha_{2}$, and $\rho$. Therefore, unless $\beta_{2}=\rho=0$, the OLS estimator of $\beta_{1}$ will be inconsistent. The large sample bias will be upward when $\rho>0$ and $\beta_{1}>0$.

\subsection{Consistent Estimation of the Contagion Coefficients}

Consistent estimation of $\beta_{i}$ can be achieved by instrumental variable techniques assuming there exists pre-determined variables specific to country $i$ that are correlated with $\mathrm{I}\left(y_{i t}-c_{i}\right)$ and uncorrelated with the errors $u_{i t}$.

If there are no country-specific regressors, namely if $\boldsymbol{\alpha}_{1}=\boldsymbol{\alpha}_{2}=0$, the contagion coefficients, $\beta_{i}$, are not identified. In this case

$$
\begin{aligned}
& y_{1 t}=\boldsymbol{\delta}_{1}^{\prime} \mathbf{z}_{t}+\beta_{1} \mathrm{I}\left(y_{2 t}-c_{2}\right)+u_{1 t}, \\
& y_{2 t}=\boldsymbol{\delta}_{2}^{\prime} \mathbf{z}_{t}+\beta_{2} \mathrm{I}\left(y_{1 t}-c_{1}\right)+u_{2 t},
\end{aligned}
$$

and the observed common drivers, $\mathbf{z}_{t}$, cannot be used as instruments for the crisis indicators. In this case pooling of the country equations will not help either, even if the slope homogeneity assumption is imposed (namely if $\boldsymbol{\delta}_{1}=\boldsymbol{\delta}_{2}$, and $\beta_{1}=\beta_{2}$ ).

If, however, country (market) specific regressors exist, i.e. $\boldsymbol{\alpha}_{i} \neq 0, i=$ 1,2 , the following instrumental variables estimator can be used. Suppose that $c_{1}$ and $c_{2}$ are known and the observations $\mathbf{y}_{t}, \mathbf{w}_{t}=\left(\mathbf{z}_{t}^{\prime}, \mathbf{x}_{1 t}^{\prime}, \mathbf{x}_{2 t}^{\prime}\right)^{\prime}, t=$ $1,2, \ldots, T$ are given and that the following conditions are met.

(i)

$$
\frac{\sum_{t=1}^{T} \mathbf{w}_{t} \mathbf{w}_{t}^{\prime}}{T} \stackrel{p}{\rightarrow} \mathbf{\Sigma}_{w w}
$$

where $\boldsymbol{\Sigma}_{w w}$ is a (non-stochastic) positive definite matrix.

(ii) Let $\mathbf{h}_{1 t}=\left(\mathbf{z}_{t}^{\prime}, \mathbf{x}_{1 t}^{\prime}, \mathrm{I}\left(y_{2 t}-c_{2}\right)\right)^{\prime}$, and $\mathbf{h}_{2 t}=\left(\mathbf{z}_{t}^{\prime}, \mathbf{x}_{2 t}^{\prime}, \mathrm{I}\left(y_{1 t}-c_{1}\right)\right)^{\prime}$, and

$$
\frac{\sum_{t=1}^{T} \mathbf{w}_{t} \mathbf{h}_{i, t}^{\prime}}{T} \stackrel{p}{\rightarrow} \mathbf{Q}_{i}
$$

where $\mathbf{Q}_{i} \quad i=1,2$ are full column rank matrices and the convergence to $\mathbf{Q}_{i}$ is uniform. 
Then the IV estimator of $\boldsymbol{\theta}_{i}=\left(\boldsymbol{\delta}_{i}^{\prime}, \boldsymbol{\alpha}_{i}^{\prime}, \beta_{i}\right)^{\prime}$, defined by

$$
\hat{\boldsymbol{\theta}}_{i}=\left(\hat{\mathbf{Q}}_{i}^{\prime} \hat{\boldsymbol{\Sigma}}_{w w}^{-1} \hat{\mathbf{Q}}_{i}\right)^{-1} \hat{\mathbf{Q}}_{i}^{\prime} \hat{\boldsymbol{\Sigma}}_{w w}^{-1} \hat{\mathbf{q}}_{i}
$$

where

$$
\hat{\mathbf{Q}}_{i}=\frac{\sum_{t=1}^{T} \mathbf{w}_{t} \mathbf{h}_{i, t}^{\prime}}{T}, \hat{\mathbf{\Sigma}}_{w w}=\frac{\sum_{t=1}^{T} \mathbf{w}_{t} \mathbf{w}_{t}^{\prime}}{T}, \hat{\mathbf{q}}_{i}=\frac{\sum_{t=1}^{T} \mathbf{w}_{t} y_{i t}}{T}
$$

is consistent for $\boldsymbol{\theta}_{i}$ as $T \rightarrow \infty$.

The validity of these conditions need to be checked in the case of the particular model under consideration. For example, suppose the model of interest is given by (16) and (17), and that the conditions (18) to (20) hold, and $T^{-1} \sum_{t=1}^{T} x_{2 t} x_{1 t}$ tends to a finite limit as $T \rightarrow \infty$. Let

$$
\operatorname{plim}_{T \rightarrow \infty}\left(\begin{array}{cc}
T^{-1} \sum_{t=1}^{T} x_{1 t}^{2} & T^{-1} \sum_{t=1}^{T} x_{1 t} \mathrm{I}\left(y_{2 t}-c_{2}\right) \\
T^{-1} \sum_{t=1}^{T} x_{2 t} x_{1 t} & T^{-1} \sum_{t=1}^{T} x_{2 t} \mathrm{I}\left(y_{2 t}-c_{2}\right)
\end{array}\right)=\mathbf{V}_{1} .
$$

Then $\alpha_{1}$ and $\beta_{1}$ can be identified if $\mathbf{V}_{1}$ has a full rank. This rank condition can be investigated using the solutions (13) and (14). Although, the exact form of $\mathbf{V}_{1}$ depends on the way the indeterminacy of the solution is resolved in periods where $-1<W_{i t}=\left(\alpha_{i} x_{i t}+u_{i t}-c_{i}\right) / \beta_{i} \leq 0$, for $i=1,2$, it would nevertheless be possible to check if $\mathbf{V}_{1}$ is full rank without a full specification of the $d_{t}$ process. For example, it suffices to postulate that $d_{t}$ follows a general Bernoulli process with a probability that varies with the state variables, $x_{i t}, i=1,2$. In the case where $x_{i t}$ and $u_{i t}$ are strictly stationary, in view of (13) and (14), it follows that $y_{i t}, i=1,2$ are also strictly stationary, and

$$
\begin{aligned}
& T^{-1} \sum_{t=1}^{T} x_{1 t} \mathrm{I}\left(y_{2 t}-c_{2}\right) \stackrel{p}{\rightarrow} \mathrm{E}\left[x_{1 t} \mathrm{I}\left(y_{2 t}-c_{2}\right)\right], \\
& T^{-1} \sum_{t=1}^{T} x_{2 t} \mathrm{I}\left(y_{2 t}-c_{2}\right) \stackrel{p}{\rightarrow} \mathrm{E}\left[x_{2 t} \mathrm{I}\left(y_{2 t}-c_{2}\right)\right] .
\end{aligned}
$$

These results, in conjunction with the solution (13) and (14) allow us to establish the rank of $\mathbf{V}_{1}$ without an exact knowledge of the $d_{t}$ process.

\section{Correlation Based Tests of Contagion}

In a number of papers by Boyer, Gibson, and Loretan (1999), Loretan and English (2000), Forbes and Rigobon (2002) and Corsetti, Pericoli and Sbracia (2002) attempts have been made to identify contagion effects from pairwise correlation of stock market returns by testing whether correlation is 
significantly higher during crises times compared to normal periods. The main difference between the studies is in how the correlation coefficient is adjusted for the higher volatility in crises periods. The studies require $a$ priori specification of the crises periods. The data employed are daily return observations and do not consider global or country-specific variables in their analysis.

In terms of our set up the basic model underlying this approach can be written as (following the approach of Corsetti et al.)

$$
\begin{aligned}
& y_{1 t}=\alpha_{1}+\beta_{1} \mathrm{I}\left(y_{2 t}-c_{2 t}\right)+u_{1 t}, \\
& y_{2 t}=\alpha_{2}+\beta_{2} \mathrm{I}\left(y_{1 t}-c_{1 t}\right)+u_{2 t},
\end{aligned}
$$

where $c_{t}$ is gleaned from the data, and the inter-dependence across the two countries is characterised using the single factor specification

$$
u_{i t}=\gamma_{i} f_{t}+\varepsilon_{i t},
$$

where $f_{t}$ is the unobserved common factor, and $\varepsilon_{i t}, i=1,2$ are idiosyncratic shocks:

$$
\begin{aligned}
f_{t} & \sim i i d(0,1), \\
\varepsilon_{i t} & \sim i i d\left(0, \sigma_{i}^{2}\right) .
\end{aligned}
$$

$f_{t}$ and $\varepsilon_{i t}$ are also assumed to be independently distributed. For the twocountry set up the single factor model is algebraically equivalent to assuming $u_{1 t}$ and $u_{2 t}$ are correlated with the correlation coefficient

$$
\rho=\frac{\gamma_{1} \gamma_{2}}{\sqrt{\sigma_{1}^{2}+\gamma_{1}^{2}} \sqrt{\sigma_{2}^{2}+\gamma_{2}^{2}}} .
$$

Under this set up there exist no valid instruments with which to identify the contagion coefficient from the inter-dependence coefficient $\rho$. The identification problem is overcome in this literature by assuming that the crises periods are known a priori, and are sufficiently prolonged and continuous so that correlation of $y_{1 t}$ and $y_{2 t}$ during crisis and non-crisis periods can be consistently estimated and compared.

Therefore, this approach is problematic on three counts.

1. The endogeneity problem discussed in the previous section is circumvented by separating crises periods from non-crises periods. Since crisis periods are identified ex post, after passing through the observations, the endogeneity bias is re-introduced, however, in form of a sample selection bias.

2. Multi-country, multi-assets (markets) generalisations of the correlation/covariance approach will require existence of much longer periods of continuous crisis for the estimation and testing strategy to be meaningful. Such data sets are unlikely to exist since by their very nature crisis periods are relatively short. 
3. The analysis can not be used in forecasting and is of limited scope in a structural understanding of the crises and the factors behind their occurrence.

\section{Contagion in a Multi-Country Setting}

Consider now a sample of $N$ countries observed over the period $t=1,2, \ldots, T$, some or all of which could be subject to a crisis at least at some times over the sample period. A generalisation of (1) and (2) to the case of $N>2$ can be written as

$$
y_{i t}=\boldsymbol{\delta}_{i}^{\prime} \mathbf{z}_{t}+\boldsymbol{\alpha}_{i}^{\prime} \mathbf{x}_{i t}+\beta_{i} \sum_{j=1}^{N} w_{i j} \mathrm{I}\left(y_{j t}-c_{j} \sigma_{j, t-1}\right)+u_{i t}, i=1,2 \ldots, N,
$$

where the weights $w_{i j} \geq 0$ are such that $\sum_{j=1}^{N} w_{i j}=1$, and $w_{i i}=0$, for all $i$. The theoretical literature on contagion can often be cast in terms of this general formulation. For example, Allen and Gale (2000) consider a theoretical model of financial contagion where bank failures spread from one region to another under different market structures. They set $N=4$ and consider three types of market structures, namely "complete", "incomplete", and "disconnected incomplete". In terms of our set up these correspond to different weighting schemes as defined by the following patterns

$$
\begin{gathered}
\mathbf{W}_{\text {Complete }}=\left(w_{i j}\right)=\left(\begin{array}{cccc}
0 & 1 / 3 & 1 / 3 & 1 / 3 \\
1 / 3 & 0 & 1 / 3 & 1 / 3 \\
1 / 3 & 1 / 3 & 0 & 1 / 3 \\
1 / 3 & 1 / 3 & 1 / 3 & 0
\end{array}\right) \\
\mathbf{W}_{\text {Incomplete }}=\left(w_{i j}\right)=\left(\begin{array}{cccc}
0 & 1 & 0 & 0 \\
0 & 0 & 1 & 0 \\
0 & 0 & 0 & 1 \\
1 & 0 & 0 & 0
\end{array}\right)
\end{gathered}
$$

and

$$
\mathbf{W}_{\text {Disconnected }}=\left(w_{i j}\right)=\left(\begin{array}{cccc}
0 & 1 & 0 & 0 \\
1 & 0 & 0 & 0 \\
0 & 0 & 0 & 1 \\
0 & 0 & 1 & 0
\end{array}\right) \text {. }
$$

Notice also that the incomplete structures pre-suppose the existence of certain ordering of the regions, although no particular ordering of the regions is required under the complete market structure. Under the disconnected incomplete structure the $N=4$ problem reduces to two separate $N=2$ problems and their solutions do not pose any new difficulties. The incomplete market pattern can be reduced to the following generalisation of (7) 
and (8)

$$
\begin{aligned}
& Y_{1 t}=W_{1 t}+\mathrm{I}\left(Y_{2 t}\right), \\
& Y_{2 t}=W_{2 t}+\mathrm{I}\left(Y_{3 t}\right), \\
& Y_{3 t}=W_{3 t}+\mathrm{I}\left(Y_{4 t}\right), \\
& Y_{4 t}=W_{4 t}+\mathrm{I}\left(Y_{1 t}\right),
\end{aligned}
$$

where as before

$$
Y_{i t}=\frac{y_{i t}-c_{i} \sigma_{i, t-1}}{\beta_{i}}, W_{i t}=\frac{\boldsymbol{\delta}_{i}^{\prime} \mathbf{z}_{t}+\boldsymbol{\alpha}_{i}^{\prime} \mathbf{x}_{i t}+u_{i t}-c_{i} \sigma_{i, t-1}}{\beta_{i}}, i=1,2,3,4
$$

The solution in this case can be obtained along similar lines followed for the simple case of $N=2$, although at the expense of much greater details. As before there will also be multiple solutions. For example, in the case where $W_{i t}=0$, two solutions are possible, namely $Y_{i t}^{a}=0$ and $Y_{i t}^{b}=1$. A complete characterisation of the solutions for all possible values of $W_{i t}$ will be beyond the scope of the present paper.

However, some interesting results can be obtained under the complete market structure. In this case (for a general $N$ ) we have

$$
y_{i t}=\boldsymbol{\alpha}^{\prime} \mathbf{x}_{i t}+\beta\left(\frac{\sum_{j=1, j \neq i}^{N} \mathrm{I}\left(y_{j t}-c_{j}\right)}{N-1}\right)+\gamma f_{t}+\varepsilon_{i t}, i=1,2 \ldots, N,
$$

where for simplicity we have omitted the common observed effects $\left(\mathbf{z}_{t}\right)$, assumed all the coefficients are homogeneous and have charachterised the inter-dependence of the errors using the single factor structure given by (23). Define the crisis indicator $\kappa_{i t}=\mathrm{I}\left(y_{i t}-c_{i}\right)$. Then,

$$
\frac{\sum_{j=1, j \neq i}^{N} \mathrm{I}\left(y_{j t}-c_{j}\right)}{N-1}=\left(\frac{N}{N-1}\right) \bar{\kappa}_{t}-\frac{1}{N-1} \kappa_{i t}
$$

where $\bar{\kappa}_{t}=N^{-1} \sum_{i=1}^{N} \kappa_{i t}$. Averaging (25) over $t=1,2, \ldots, T$, we have ${ }^{5}$

$$
\bar{y}_{t}=\boldsymbol{\alpha}^{\prime} \overline{\mathbf{x}}_{t-1}+\beta \bar{\kappa}_{t}+\gamma f_{t}+\bar{\varepsilon}_{t} .
$$

Using this result in (25) to eliminate the unobserved common effect, $f_{t}$, we have

$$
\begin{aligned}
y_{i t} & =\boldsymbol{\alpha}^{\prime} \mathbf{x}_{i t}+\beta\left[\left(\frac{N}{N-1}\right) \bar{\kappa}_{t}-\frac{1}{N-1} \kappa_{i t}\right]+\left(\bar{y}_{t}-\boldsymbol{\alpha}^{\prime} \overline{\mathbf{x}}_{t}-\beta \bar{\kappa}_{t}-\bar{\varepsilon}_{t}\right)+\varepsilon_{i t}, \\
i & =1,2 \ldots, N
\end{aligned}
$$

\footnotetext{
${ }^{5}$ See Pesaran (2002) for a general discussion of the analysis of cross-sectional dependence in large panels.
} 
Hence

$$
y_{i t}-\bar{y}_{t}=\boldsymbol{\alpha}^{\prime}\left(\mathbf{x}_{i t}-\overline{\mathbf{x}}_{t}\right)-\beta\left(\frac{\kappa_{i t}-\bar{\kappa}_{t}}{N-1}\right)+\left(\varepsilon_{i t}-\bar{\varepsilon}_{t}\right) .
$$

In the case where $N$ is sufficiently large, the second term converges to zero and $\beta$ cannot be identified, although a consistent estimator of $\boldsymbol{\alpha}$ can be obtained from an OLS regression of $y_{i t}-\bar{y}_{t}$ on $\left(\mathbf{x}_{i t}-\overline{\mathbf{x}}_{t}\right)$. Allowing for parameter heterogeneity does not resolve this problem. For $N$ fixed as $T \rightarrow$ $\infty$, the condition for identification of $\beta$ is similar to the two-country case discussed in Section 6 above.

\section{Panel Estimates of Contagion}

Eichengreen, Rose and Wyplosz (1996, 1997), Esquivel and Larrain (1998), Kruger, Osakwe and Page (1998), Kumar, Moorthy and Perraudin (2002) and Stone and Weeks (2001) attempt to estimate and test for contagion effects using panel data. The econometric approach taken in these papers is based on binary choice models with linear index functions

$$
y_{i t}=\alpha_{0 i}+\boldsymbol{\alpha}^{\prime} \mathbf{x}_{i t}+\varepsilon_{i t}, \quad \text { for } i=1,2, \ldots, N, t=1,2, \ldots, T
$$

where $y_{i t}$ is a latent variable observed qualitatively through a univariate binary response indicator, $\kappa_{i t}=\mathrm{I}\left(y_{i t}\right)$, the currency crisis indicator. $\mathbf{x}_{i t}$ is a $k \times 1$ vector of observed macroeconomic and political variables, $\boldsymbol{\alpha}$ is a $k \times 1$ vector of unknown coefficients and $\varepsilon_{i t}$ is an idiosyncratic error assumed to be serially uncorrelated for each $i$, and iid normal distributed across $i$ with mean zero, a unit variance. Except for the paper by Esquivel and Larrain (1998), who use a random effects probit model, the literature assumes that $\alpha_{0 i}=\alpha_{0}$.

Contagion is addressed by including a dummy variable, $\mathcal{C}_{i t}$, in model (26),

$$
y_{i t}=\alpha_{0 i}+\beta \mathcal{C}_{i t}+\boldsymbol{\alpha}^{\prime} \mathbf{x}_{i t}+\varepsilon_{i t},
$$

where

$$
\mathcal{C}_{i t}=\mathrm{I}\left(\sum_{j=1, j \neq i}^{N} \kappa_{j t}\right) .
$$

Under this formulation the crisis indicator, $\mathcal{C}_{i t}$, takes the value of unity if any one of the $N-1$ remaining countries find themselves in a crisis state. This formulation is quite similar to that discussed above and is subject to similar identification and estimation issues. Due to the non-linear nature of this formulation, in order to assess the impact of the endogeneity on the parameter estimates in the probit model of (26) we conduct a Monte Carlo experiment using the data of Eichengreen et al. (1996). Details of the data are given in the Appendix 12. 


\subsection{Experimental Design}

The Monte Carlo experiments are based on the following data generating process (DGP):

$$
y_{i t}^{r}=\alpha_{0}+\boldsymbol{\alpha}^{\prime} \mathbf{x}_{i t}^{r}+u_{i t}^{r},
$$

where $i=1,2, \ldots, N, t=1,2, \ldots, T, r=1,2, \ldots, R, r$ refers to the replication number in the Monte Carlo experiments, $R$ is the total number of replications, $\boldsymbol{\alpha}$ is a $k \times 1$ vector of parameters, $\mathbf{x}_{i t}^{r}$ is a $k \times 1$ vector of simulated exogenous variables. Under this DGP, $\boldsymbol{\beta}=\mathbf{0}$ and all other coefficients are assumed to be identical across $i$.

The estimation of $\alpha_{0}$ and $\boldsymbol{\alpha}$ under a probit specification only makes use of $\kappa_{i t}^{r}=\mathrm{I}\left(y_{i t}^{r}\right)$ and, hence, without loss of generality the variance of the error term, $u_{i t}^{r}$, may be set equal to unity. To allow for correlation across the errors of different cross section units we adopt the following standardised one-factor structure

$$
u_{i t}^{r}=\frac{\gamma_{i} f_{t}^{r}+\varepsilon_{i t}^{r}}{\sqrt{1+\gamma_{i}^{2}}}
$$

where $\gamma_{i}$ is a scalar, $f_{t}^{r} \sim \operatorname{iidN}(0,1)$, and $\varepsilon_{i t}^{r} \sim \operatorname{iidN}(0,1)$. Under these assumptions we have $\mathrm{E}\left(u_{i t}^{r}\right)=0$ and $\operatorname{Var}\left(u_{i t}^{r}\right)=1$. The pairwise correlation coefficient of the errors is given by

$$
\operatorname{Corr}\left(u_{i t}^{r}, u_{j t}^{r}\right)=\frac{\gamma_{i} \gamma_{j}}{\sqrt{\left(1+\gamma_{i}^{2}\right)\left(1+\gamma_{j}^{2}\right)}} .
$$

Regarding values of $y_{i t}^{r}>0$ as crisis, in all our experiments we fix $\alpha_{0}$ such that the fraction of observations, $\pi$, with $y_{i t}^{r}>0$ is non-zero but relatively small, namely $\pi=5 \%$. For this purpose, assuming that the regressors are normally distributed we have $\boldsymbol{\alpha}^{\prime} \mathbf{x}_{i t}+u_{i t} \sim \operatorname{iidN}\left(0,1+\boldsymbol{\alpha}^{\prime} \Sigma_{x} \boldsymbol{\alpha}\right)$ and therefore

$$
\operatorname{Pr}\left(y_{i t}^{r}>0\right)=\operatorname{Pr}\left(\boldsymbol{\alpha}^{\prime} \mathbf{x}_{i t}^{r}+u_{i t}^{r}>-\alpha_{0}\right)=1-\Phi\left(\frac{-\alpha_{0}}{\sqrt{1+\boldsymbol{\alpha}^{\prime} \mathbf{\Sigma}_{x} \boldsymbol{\alpha}}}\right)=\pi .
$$

Hence, we set

$$
\alpha_{0}=-\left(1+\boldsymbol{\alpha}^{\prime} \boldsymbol{\Sigma}_{x} \boldsymbol{\alpha}\right)^{1 / 2} \Phi^{-1}(1-\pi) .
$$

This is an important choice in the Monte Carlo experiment because the contagion dummy becomes a vector of ones if the proportion of crises periods is too high and then the right hand side variables are perfectly collinear as they contain an intercept and the contagion dummy. On the other hand, data sets without crises are meaningless for the concept of contagion and the estimation of a probit model is not possible.

For each replication a contagion dummy, $\mathcal{C}_{i t}^{r}$, is constructed as

$$
\mathcal{C}_{i t}^{r}=\mathrm{I}\left(\sum_{j=1, j \neq i}^{N} \kappa_{j t}^{r}\right) .
$$


For the probit estimation only the binary indicator $\kappa_{i t}^{r}=\mathrm{I}\left(y_{i t}^{r}\right)$ is observed. The probability of $\kappa_{i t}^{r}=1$ is modelled as

$$
\operatorname{Pr}\left(\kappa_{i t}^{r}=1\right)=\Phi\left(\alpha_{0}+\beta \mathcal{C}_{i t}^{r}+\boldsymbol{\alpha}^{\prime} \mathbf{x}_{i t}^{r}\right),
$$

and for the linear OLS regression the assumed model is

$$
y_{i t}^{r}=\alpha_{0}+\beta \mathcal{C}_{i t}^{r}+\boldsymbol{\alpha}^{\prime} \mathbf{x}_{i t}^{r}+e_{i t}^{r},
$$

where $e_{i t}^{r} \sim \operatorname{iid}\left(0, \sigma_{e}^{2}\right)$. The parameters of the probit model (in particular the contagion coefficient, $\beta$ ) are computed by the maximum likelihood method.

In a first set of Monte Carlo experiments, we generate $\mathbf{x}_{i t}^{r} \sim \operatorname{iid}\left(\mathbf{0}, \boldsymbol{\Sigma}_{x}\right)$ for two values of $k$, namely $k=1$ and $k=2$. We fix $\boldsymbol{\Sigma}_{x}$ implicitly by generating the regressors with the following common factor structure

$$
x_{i t}^{r}=\frac{1}{\sqrt{1+\phi_{i}}}\left(q_{i t}^{r}+\phi_{i} h_{t}^{r}\right)
$$

where $q_{i t}^{r} \sim \operatorname{iidN}(0,1)$, and $h_{t}^{r} \sim \operatorname{iidN}(0,1)$. To ensure that the regressors are distributed independently of the errors, $h_{t}^{r}$ and $f_{t}^{r}$ are taken to be independent draws. Finally, without loss of generality we set $\boldsymbol{\alpha}=\boldsymbol{\iota}_{k}$, a $k \times 1$ vector of ones. Note that under $\phi_{i}=0, \boldsymbol{\Sigma}_{x}=\mathbf{I}_{k}$, and using (28) we have $\alpha_{0}=1.96(\sqrt{1+k})$ for $\pi=0.025$, and $\alpha_{0}=1.64(\sqrt{1+k})$ for $\pi=0.05$. In the case where $\phi_{i}>0, \boldsymbol{\Sigma}_{x}$ will have typical off diagonal elements $\sigma_{i j}=\phi_{i} \phi_{j} /\left(\sqrt{1+\phi_{i}} \sqrt{1+\phi_{j}}\right)$, and $\alpha_{0}$ follows from (28).

Note that, while we appreciate that parameter heterogeneity may be important in applications, we abstract from it in the Monte Carlo experiment for simplicity. Intercept heterogeneity could be introduced via a random effects probit model or a conditional logit model, see Hsiao (2003).

In a second set of Monte Carlo experiments the exogenous regressors of Eichengreen et al. (1996, ERW) are used and taken as given across all the replications. Under the null of no contagion $\beta$ is set equal to zero and the other parameters, $\left(\alpha_{0}, \boldsymbol{\alpha}\right)$, are set equal to the estimates of the pooled probit model computed using the ERW data. These estimates are given in Table 2 . 
Table 2: Probit model with ERW data

\begin{tabular}{lrr}
\hline \hline variable & $\left(\hat{\alpha}_{0}, \hat{\boldsymbol{\alpha}}\right)$ & $|t|$-value \\
\hline Intercept $\left(\hat{\alpha}_{0}\right)$ & -1.886 & 10.751 \\
Capital controls & -0.134 & 0.717 \\
Government victory & -0.060 & 1.141 \\
Government loss & -0.332 & 0.787 \\
Credit growth & 0.016 & 1.880 \\
Inflation & 0.065 & 3.584 \\
Output growth & 0.020 & 0.732 \\
Employment growth & 0.043 & 1.007 \\
Unemployment rate & 0.073 & 3.010 \\
Budget position & 0.042 & 2.042 \\
Current account & -0.024 & 1.072 \\
\hline \hline
\end{tabular}

Total number of observations $=645$

Hence, a vector $\mathbf{y}^{r}$ is generated as

$$
y_{i t}^{r}=\hat{\alpha}_{0}+\hat{\boldsymbol{\alpha}}^{\prime} \mathbf{x}_{i t}+u_{i t}^{r}
$$

The specification of the error term and the estimation are as in the case of artificial data.

\subsection{Results of the Monte Carlo Experiments}

\subsubsection{Results for the Simulated Regressors}

Tables 3-8 give the results for the Monte Carlo experiments with artificially generated regressors. Tables 3 and 4 report the results for $k=1$, Tables 5 and 6 for $k=2$ with orthogonal regressors, and Tables 7 and 8 , report the results for $k=2$ where the regressors are correlated with $\phi_{i}=0.5, \forall i$. The first of each pair of tables uses only a discretised dependent variable and estimates a probit model, while the second uses the continuous dependent variable and estimates the model by OLS.

It can be seen that throughout all experiments the bias increases with the size of the correlation of the error term across $i$. For small and even medium sample sizes the estimate of $\beta$ is quite imprecise in the probit model even under $\gamma=0$. However, the OLS estimates of the contagion effects $(\beta)$ under error inter-dependence $\left(\rho=\gamma^{2} /\left(1+\gamma^{2}\right) \neq 0\right)$ is positive in all the experiments, confirming the upward bias derived theoretically in the context of our simple two-country canonical model.

The last panel of each table gives the rejection probability for the hypothesis of no contagion, i.e. $\beta=0$. It can be seen that the rejection probability rises as inter-dependence increases. With $\gamma=1$, that is with error correlation $0.5, N=100$ and $T=100$ the hypothesis of no contagion is always rejected in all models. However, even mild inter-dependence leads 
to high rejection rates. In the OLS estimation with $k=1, \gamma=0.4$, which implies correlation of 0.14 , and $N=T=50$ the hypothesis of no contagion is rejected in $97.3 \%$ of cases. It can also be seen that the probit model has poor size, over-rejecting the null in all cases.

A further interesting result is that even for homogeneous $\gamma$ the precision of the estimates does not improve equally with increasing $N$ and $T$. It is clear that for all the experiments the root mean square errors are systematically lower with $T$ larger than $N$ for a given value of the product $N \times T$. For example in Table 3, for $\gamma=1$, the RMSE is 1.192 for $T=50, N=100$, and 1.055 for $T=100, N=50$. The intuition behind this is the way the contagion variable is constructed, which means that the information contents of increasing $N$ and $T$ are not the same. Recall that the contagion variable is 1 for all $i$ if there are at least two crises in the period, and hence the effect of increasing $N$ will be limited.

\subsubsection{Results Based on the ERW Regressors}

The pooled OLS and pooled probit results for this case are summarised in Table 9. Both sets of results clearly show an upward bias in the estimates of the contagion coefficient for non-zero values of $\gamma$, with the bias increasing steadily with $\gamma$. The bias could be substantial even for moderate degrees of cross dependence. For example, for $\gamma=0.4$ (which corresponds to a pairwise cross correlation coefficient of around 0.14) the pooled panel estimate of $\beta$ is 0.27 as compared to its true value of zero. This result holds both under homogeneous and heterogeneous $\gamma^{\prime} s$, and estimation procedures.

The null hypothesis of $\beta=0$ is also rejected well in excess of the nominal $5 \%$ level for all non-zero values of $\gamma$. The pooled probit estimates also exhibit a substantial degree of over-rejection (12.3\% as compared to $5 \%$ ) even under $\gamma=0$. The degree of over-rejection of the pooled OLS estimates $(7.2 \%)$ is much less pronounced, although still significantly different from $5 \%$ considering that the experiments are based on 2000 replications.

In view of these results it is reasonable to conclude that the estimate of the contagion coefficient of 0.54 that one obtains from pooled probit estimation using the ERW data could be wholly or partly due to neglected inter-dependencies of the equation errors across different countries.

\section{Conclusion}

In this paper we have developed a canonical model of contagion. Using this model, we have considered the issue of identification and consistent estimation of contagion coefficients. We show that in the presence of error inter-dependencies contagion effects cannot be consistently estimated without country-specific fundamentals. This clearly highlights some of the pitfalls that surround the empirical studies of currency crises and financial 
contagions that are extant in the literature. Correlation analysis that looks for significant shifts in correlation coefficients across the crisis and tranquil periods are usually based on high frequency data (daily or weekly) for which there are no observations on country specific fundamentals. In the case of such data sets identification of contagion is achieved by making strong $a$ priori assumptions concerning sample splits into "crisis" and "no-crisis" periods. Invariably, this also involves the identification of the source country in which the crisis is purported to have begun.

Multi-country panel analyses of the type carried out by ERW do contain country specific fundamentals and could in principle be used to shed light on the issue of contagion versus inter-dependence. However, panel data studies are typically carried out assuming that contagion indices are exogenous and that errors across countries/markets are independently distributed, and as we have shown this could introduce a substantial upward bias in the estimates of the contagion coefficients. A simultaneous estimation of inter-dependence and contagion effects are required. The canonical model presented in this paper could be viewed as a first step towards such an objective.

\section{Appendix: Simulation of $\mathbf{E}\left[u_{2 t} I\left(y_{1 t}-c_{1}\right)\right]$}

Table A reports the simulated values of $\mathrm{E}\left[u_{2 t} \mathrm{I}\left(y_{1 t}-c_{1}\right)\right]$ using $\sum_{t=1}^{T}\left[u_{2 t} \mathrm{I}\left(y_{1 t}-c_{1}\right)\right] / T$ with $T=2,000,000$. The data are generated from the reduced form of the model given by Equations (13) and (14) with $k=1, x_{i t}, u_{i t} \sim \operatorname{iid} \mathrm{N}(0,1)$, $\operatorname{Pr}\left(d_{t}=1\right)=0.50$, and $c_{i}=1.64$. It can be seen that only for $\rho=\beta=0$ the simulated value is zero. Similar results are also obtained for other choices of the solution indicator, $d_{t}$, namely $d_{t}=0$, or $d_{t}=1$. 


\begin{tabular}{rrrrrrr}
\multicolumn{6}{c}{ Table A: Simulated Values of $\sum_{t=1}^{T}\left[u_{2 t} \mathrm{I}\left(y_{1 t}-c_{1}\right)\right] / T$} \\
\hline \hline \multicolumn{2}{c}{$\beta$} & $\beta$ & \multicolumn{5}{c}{$\alpha$} \\
\cline { 2 - 7 } & & -4 & -1 & 0 & 1 & 4 \\
\hline-0.99 & -4 & -0.095 & -0.143 & -0.103 & -0.142 & -0.096 \\
& -1 & -0.092 & -0.143 & -0.103 & -0.142 & -0.092 \\
& 0 & -0.089 & -0.142 & -0.103 & -0.143 & -0.088 \\
& 1 & -0.082 & -0.140 & -0.103 & -0.140 & -0.083 \\
& 4 & -0.054 & -0.037 & -0.024 & -0.039 & -0.053 \\
-0.50 & -4 & -0.056 & -0.077 & -0.052 & -0.077 & -0.056 \\
& -1 & -0.050 & -0.075 & -0.052 & -0.075 & -0.050 \\
& 0 & -0.045 & -0.072 & -0.052 & -0.072 & -0.044 \\
& 1 & -0.036 & -0.051 & -0.040 & -0.051 & -0.037 \\
& 4 & -0.011 & 0.030 & 0.023 & 0.031 & -0.011 \\
0.00 & -4 & -0.018 & -0.017 & -0.005 & -0.017 & -0.017 \\
& -1 & -0.007 & -0.010 & -0.004 & -0.010 & -0.008 \\
& 0 & 0.000 & 0.000 & -0.000 & 0.000 & -0.000 \\
& 1 & 0.008 & 0.040 & 0.045 & 0.041 & 0.008 \\
& 4 & 0.032 & 0.089 & 0.060 & 0.090 & 0.032 \\
0.50 & -4 & 0.022 & 0.035 & 0.026 & 0.035 & 0.021 \\
& -1 & 0.036 & 0.053 & 0.036 & 0.052 & 0.036 \\
& 0 & 0.045 & 0.072 & 0.052 & 0.072 & 0.045 \\
& 1 & 0.055 & 0.128 & 0.135 & 0.128 & 0.055 \\
& 4 & 0.075 & 0.134 & 0.082 & 0.134 & 0.074 \\
0.99 & -4 & 0.060 & 0.078 & 0.010 & 0.078 & 0.060 \\
& -1 & 0.078 & 0.112 & 0.047 & 0.112 & 0.079 \\
& 0 & 0.089 & 0.142 & 0.103 & 0.142 & 0.089 \\
& 1 & 0.099 & 0.208 & 0.213 & 0.207 & 0.099 \\
& 4 & 0.114 & 0.165 & 0.070 & 0.166 & 0.115 \\
\hline \hline
\end{tabular}

The results are from data generated according to Equations (13) and (14), with $k=1, x_{i t}, u_{i t} \sim \operatorname{iid~N}(0,1), \operatorname{Pr}\left(d_{t}=1\right)=0.5, c_{i}=1.64$, and $T=2,000,000$.

\section{Data Appendix}

The data set used by Eichengreen et al. $(1996,1997)$ is available on the internet at

http://haas.berkeley.edu/ arose/RecRes.htm

along with a Stata log file. The description of the data is identical in Eichengreen et al. (1996, pp. 477-478) and (1997, pp. 23-25).

According to Eichengreen et al. (1997, p. 23) "[t]he data set is quarterly, spanning 1959 through 1993 for twenty industrial countries." The countries are the USA, UK, Austria, Belgium, Denmark, France, Italy, Netherlands, 
Norway, Sweden, Switzerland, Canada, Japan, Finland, Greece, Ireland, Portugal, Spain, Australia and Germany as the centre country. "Most of the variables are transformed into differential percentage changes by taking differences between domestic and German annualised fourth-differences of natural logarithms and multiplying by a hundred." (Eichengreen et al. 1997, p. 23).

The variables are: Total non-gold international reserves (IMF IFS line 1ld), exchange rate with US dollar (rf), money market rates (60b) or where unavailable discount rates (60), exports and imports (70 and 71), the current account (80) and the central governments budget position (80) both as percentages of nominal GDP (99a), long term bond yields (61), nominal stock market index (62), domestic credit (32), M1 (34), M2 (35 + M1), CPI (64), real GDP (99a.r), and relative unit labour cost (reu). Further from the OECD's Main Economic Indicators employment and unemployment, and Eichengreen et al. construct "indicators of government electoral victories and defeats, using Keesing's Record of World Events and the World Banks' Political Handbook of the World." (Eichengreen et al. 1997, p. 24)

Eichengreen et al. use the following definition of the exchange-rate market pressure index

$$
E M P_{i t}=\lambda_{1} \% \Delta e_{i t}+\lambda_{2} \% \Delta\left(r_{i t}-r_{G t}\right)-\lambda_{3}\left(\% \Delta f_{i t}-\% \Delta f_{G t}\right),
$$

where $e_{i t}$ is the exchange rate to the US Dollar, $r_{i t}$ the interest rate, and $f_{i t}$ the international reserves of country $i$. Subscript $G$ indicates variables for Germany, which is taken as the center country. Eichengreen et al. (1997, pp.23-24) say that they "weight the components so as to equalize the volatility of the three components". This is accomplished by setting $\lambda_{i}=1 / \sigma_{i}$, where $\sigma_{i}$ is the standard deviation of component $i$. For this data set $\sigma_{1}=0.243, \sigma_{2}=0.037$, and $\sigma_{3}=0.0047$.

The crisis index is the calculated as

$$
y_{i t}= \begin{cases}1 & E M P_{i t}>\mu_{E M P}+1.5 \sigma_{E M P} \\ 0 & \text { otherwise }\end{cases}
$$

where $\mu_{E M P}$ is the mean and $\sigma_{E M P}$ is the standard deviation of the exchange rate market pressure index.

The credit growth, the inflation rate, the output growth and the current account are calculated as

$$
d x_{i t}=100 * \ln \left(x_{i t} / x_{i t-4}\right)-\ln \left(x_{G t} / x_{G t-4}\right),
$$

where $x_{i t}$ is the variable for country $i$ and Germany, $G$. The relative unemployment rate is $d x_{i t}=x_{i t}-x_{G t}$. The relative budget position is defined as $d b_{i t}=b_{i t} / y_{i t}-b_{G t} / y_{G t}$, where $b_{i t}$ is the nominal government budget of country $i, y_{i t}$ is the GDP of country $i$ and Germany, $G$. The dummies for 
capital controls, government electoral victory and government electoral loss are not transformed. The other variables mentioned above are not used.

"To avoid counting the same crisis more than once, we exclude the later observation(s) when two (or more) crises occur in successive quarters." (Eichengreen et al. 1997, p.22) Country by country excluding time periods with missing data results in 645 observations for 17 countries with 56 crises observations. The countries are the USA, the UK, Austria, Belgium, Denmark, France, Germany, Italy, the Netherlands, Norway, Canada, Japan, Finland, Greece, Ireland, Portugal, Spain, and Australia.

\section{References}

Allen, Franklin and Douglas Gale (2000), 'Financial Contagion', Journal of Political Economy, 108(1), 1-33.

Amemiya, Takeshi (1985) Advanced Econometrics (Oxford: Basil Blackwell)

Bae, Kee-Hong, G. Andrew Karolyi, and René M. Stulz (2003) 'A new approach to measuring financial contagion.' Review of Financial Studies 16(3), 717-763

Boyer, Brian H., Michael S. Gibson, and Mico Loretan (1999) 'Pitfalls in tests for changes in correlation.' Federal Reserve Board International Finance Discussion Paper 597

Corsetti, Giancarlo, Marcello Pericoli, and Massimo Sbracia (2002) "Some contagion, some interdependence': More pitfalls in tests of financial contagion.' mimeo, University of Rome III

Dungey, Mardi, Renée Fry, Brenda González-Hermosillo and Vance L. Martin (2003), 'Empirical modelling of contagion: A review of methodologies.', mimeo, CERF, Cambridge University

Dornbusch, Rudiger, Yung Chul Park, and Stijn Claessens (2000), 'Contagion: Understanding how it spreads', World Bank Research Observer, 15(2), 177-97

Eichengreen, Barry, Andrew K. Rose, and Charles Wyplosz (1996) 'Contagious currency crises: First tests.' Scandinavian Journal of Economics 98(4), 463-484

- (1997) 'Contagious currency crises.' mimeo, UC Berkeley

Embrechts, P., C. Klüppelberg, and T. Mikosch (1997) Modelling Extremal Events for Insurance $\&$ Finance (Berlin: Springer Verlag)

Esquivel, Gerardo, and Felipe Larraín B. (1998) 'Explaining currency crises.' mimeo, Harvard University

Favero, Carlo, A. and Francesco Giavazzi, (2002), 'Is the international propagation of financial shocks non-linear? Evidence from the ERM.', Journal of International Economics, 57, 231-46

Forbes, Kristin, and Roberto Rigobon (2001) 'Measuring contagion: Con- 
ceptual and empirical issues.' In International Financial Crises, ed. Stijn Claessens and Kristin J. Forbes (Boston: Kluwer) pp. 43-66

- (2002) 'No contagion, only interdependence: Measuring stock market co-movements.' Journal of Finance 57(5), 2223-2261

Hsiao, Cheng (2003), Analysis of Panel Data, 2nd edition (Cambridge: Cambridge University Press)

King, Mervyn A. and Sushil Wadhwani (1990), 'Transmission of volatility between stock markets' Review of Financial Studies, 3(1), 5-33

Kruger, Mark, Patrick N. Osakwe, and Jennifer Page (1998) 'Fundamentals, contagion and currency crises: An empirical analysis' Bank of Canada Working Paper 98-10

Kumar, Mohan, Uma Moorthy, and William Perraudin (2002) 'Predicting emerging market currency crashes.' IMF Working Paper $02 / 7$

Loretan, Mico, and William B. English (2000) 'Evaluating "correlation breakdowns" during periods of market volatility.' In International Financial Markets and the Implication for Monetary and Financial Stability, ed. Bank for International Settlements (Basle: Bank for International Settlements)

Masson, Paul R. (1999) 'Contagion: Monsoonal effects, spillovers, and jumps between multiple equilibria.' In The Asian Crises: Causes, Contagion and Consequences, ed. P. Agénor, M. Miller, and D. Vines (Cambridge: Cambridge University Press)

Pericoli, Marcello, and Massimo Sbracia (2002) 'A primer on financial contagion.' Journal of Economic Surveys, 17(4), 571-608

Pesaran, M. Hashem (2002) 'Estimation and inference in large heterogeneous panels with cross section dependence' mimeo, University of Cambridge

Sachs, Jeffrey, Aaron Tornell and Andrés Velasco (1996) 'Financial Crises in Emerging Markets: The Lessons from 1995' Brookings Papers on Economic Activity 1, 147-215

Stone, Mark R., and Melvyn Weeks (2001) 'Systemic financial crises, balance sheets, and model uncertainty.' IMF Working Paper 01/162 


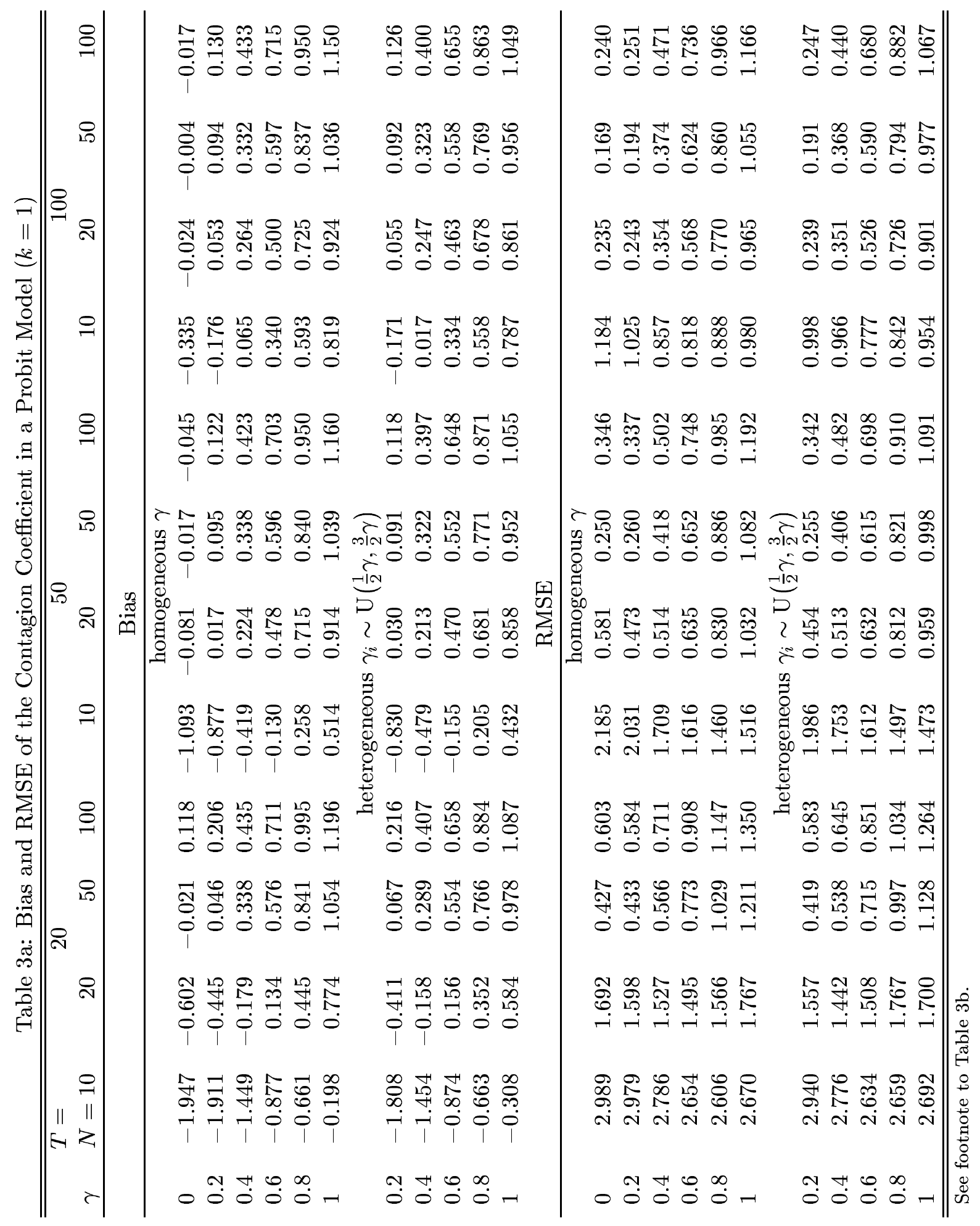




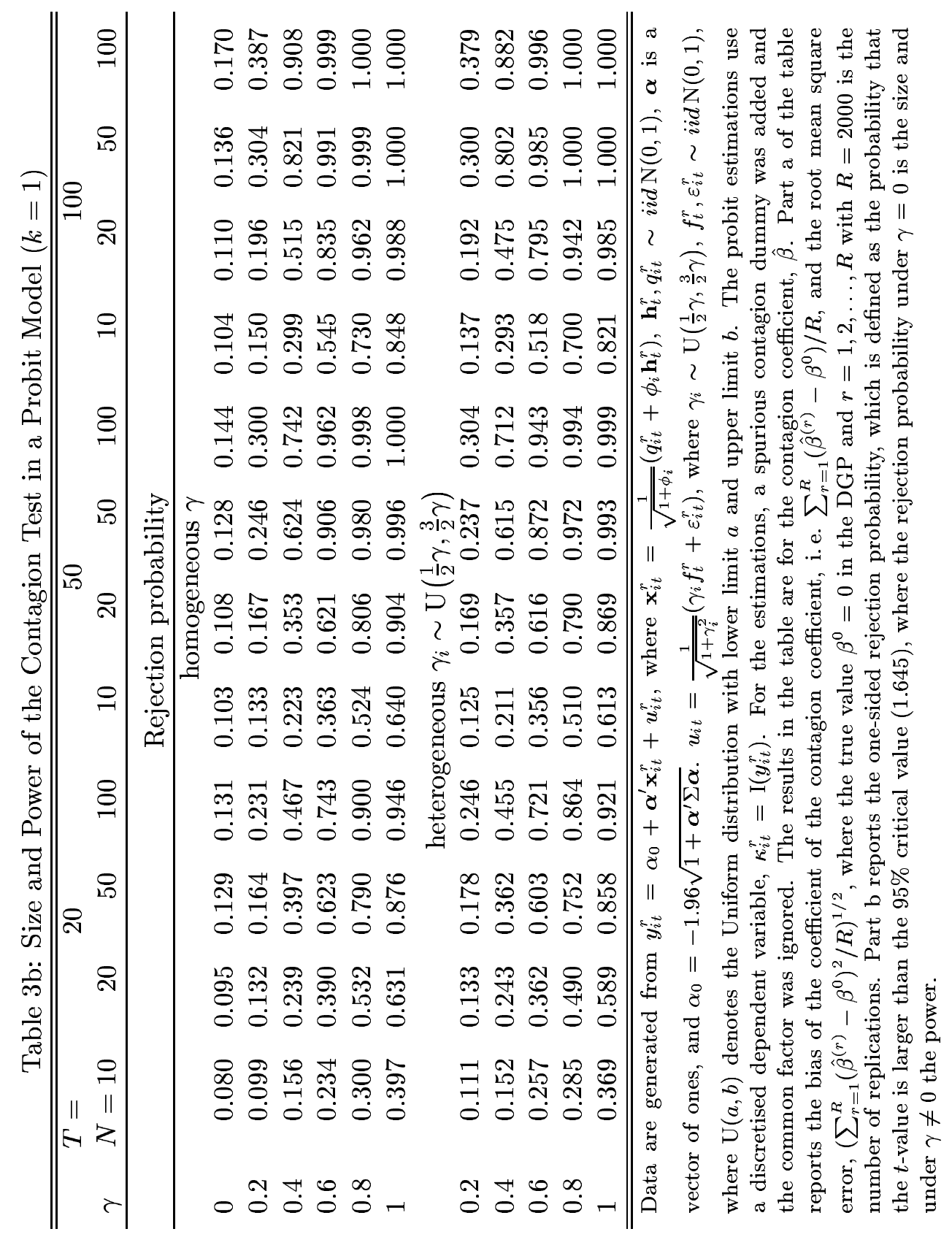




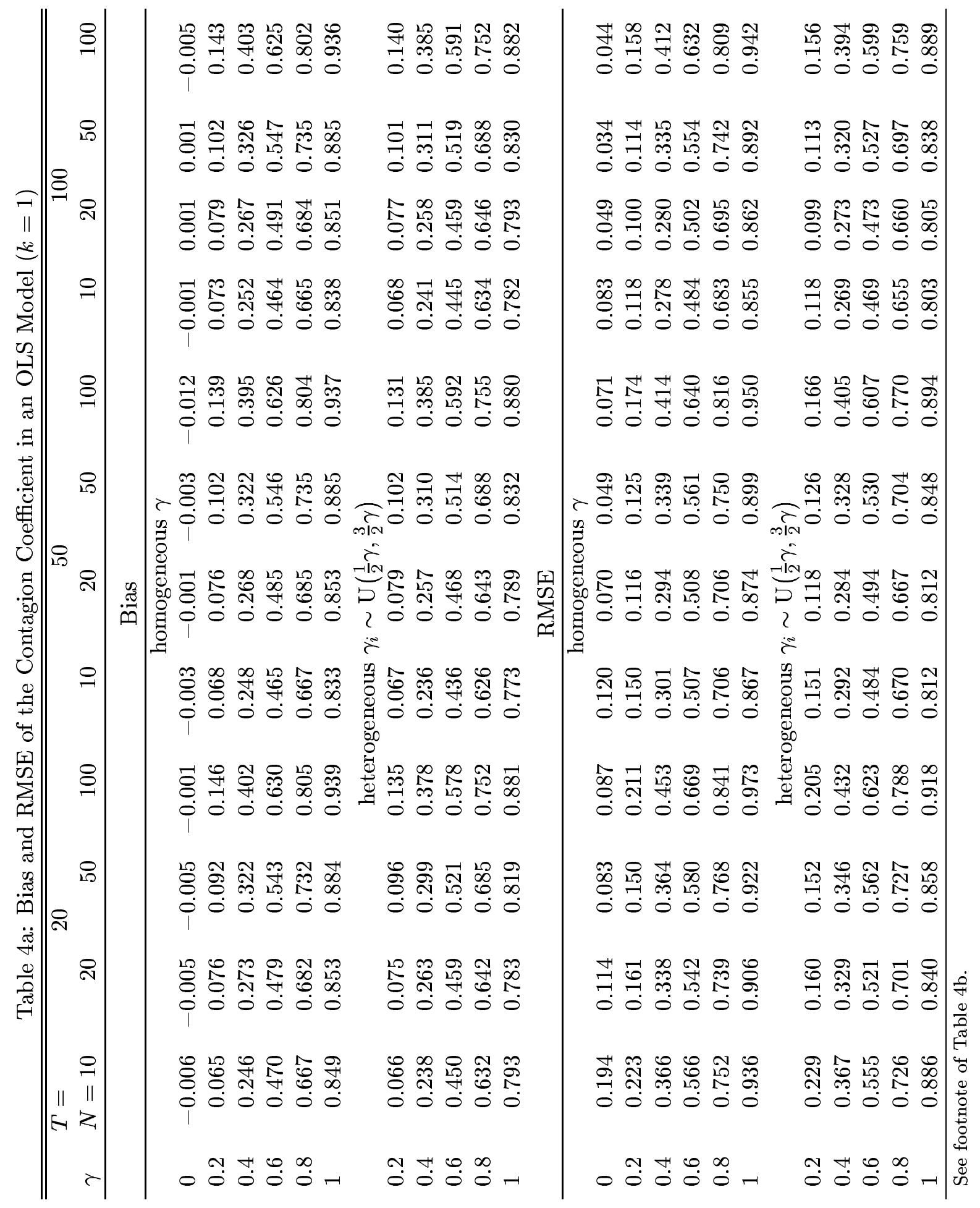




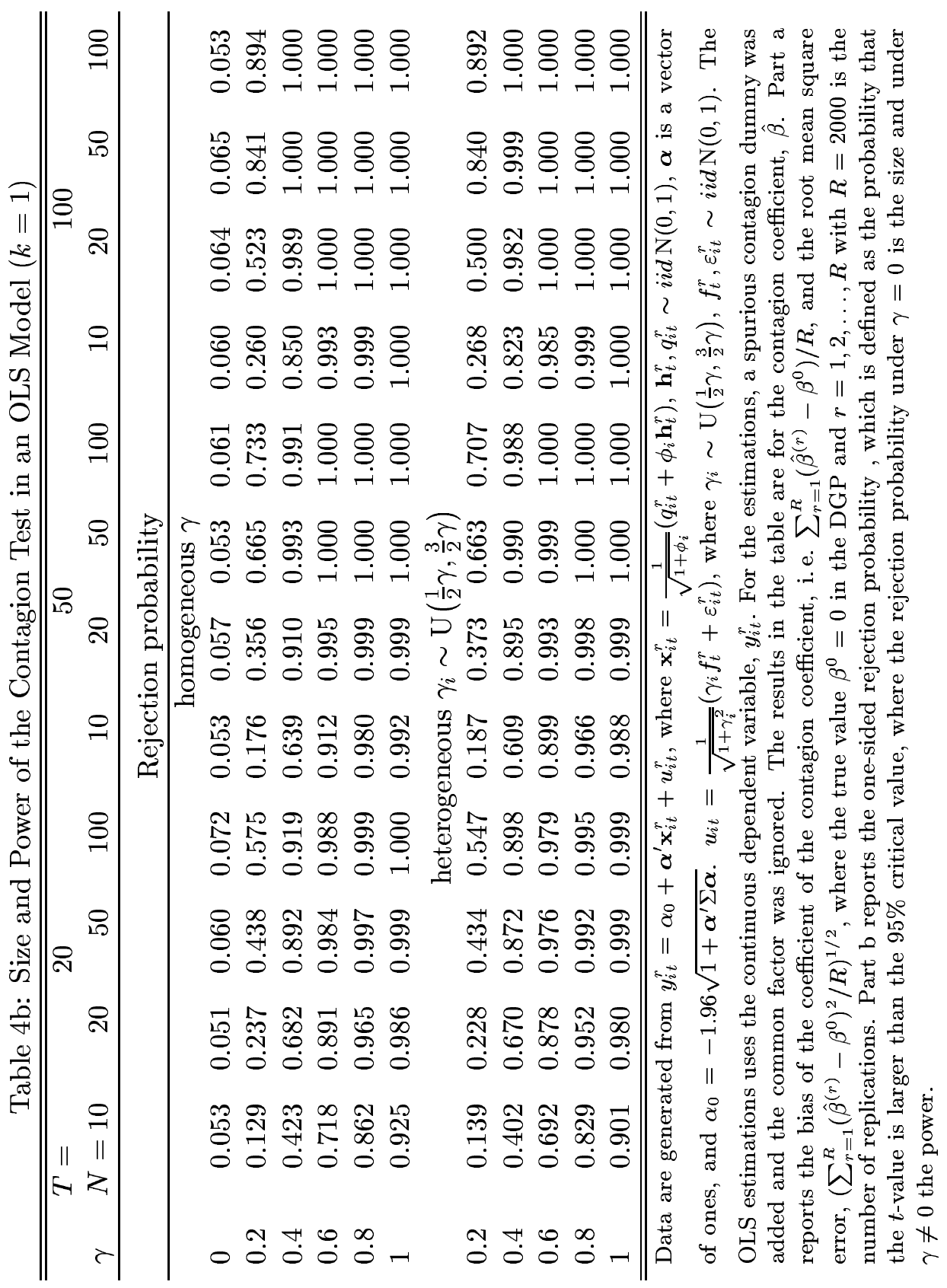




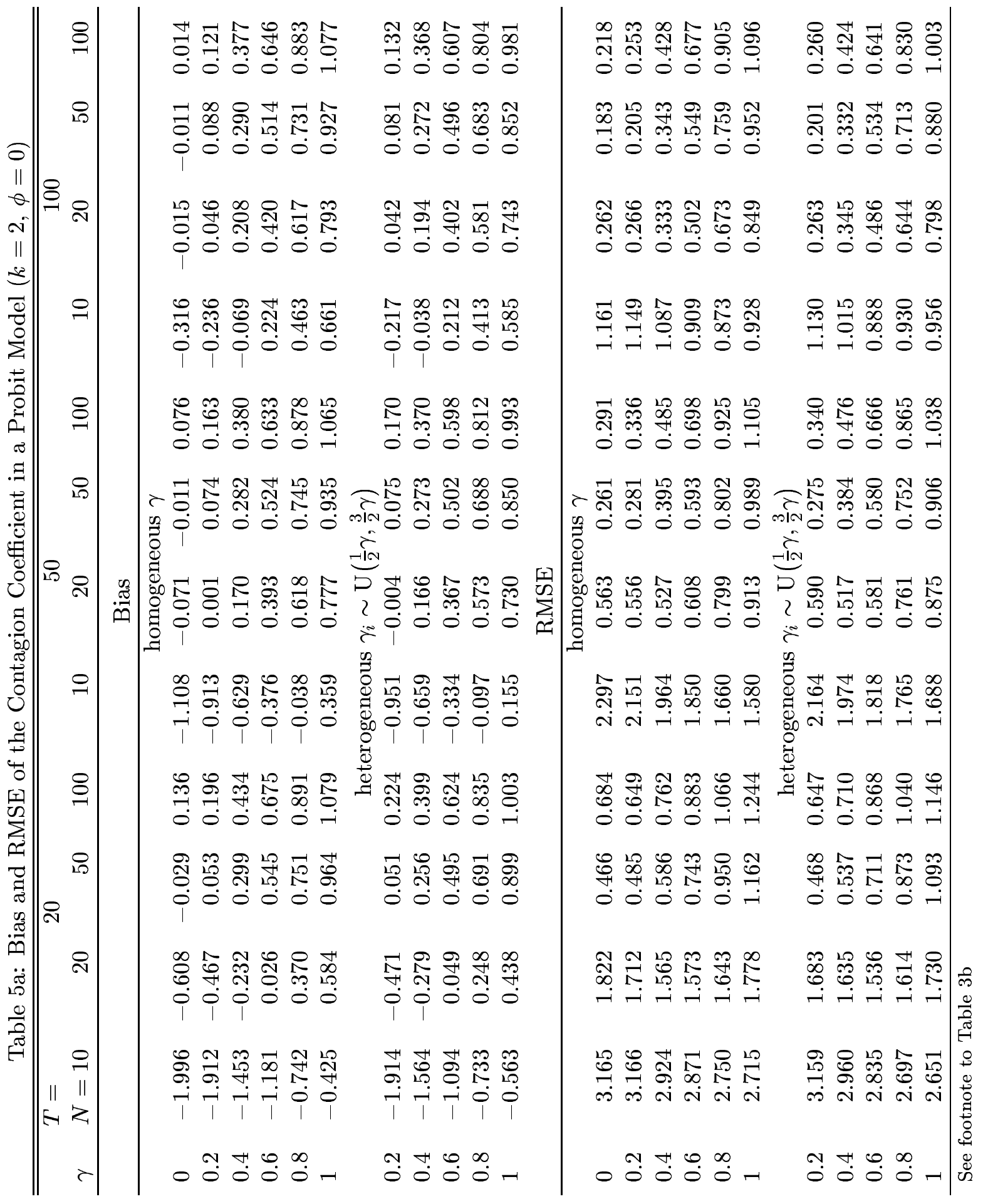




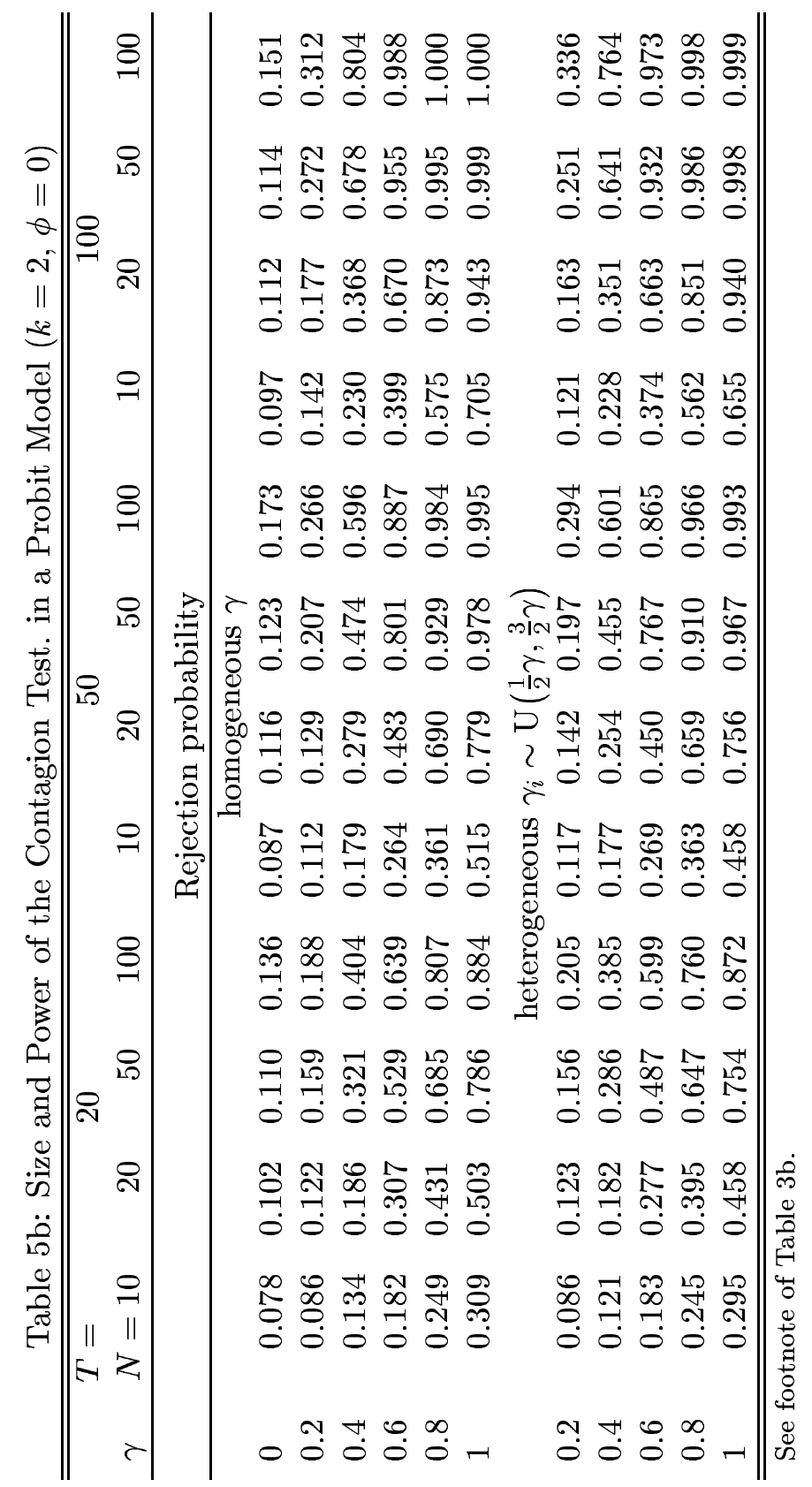




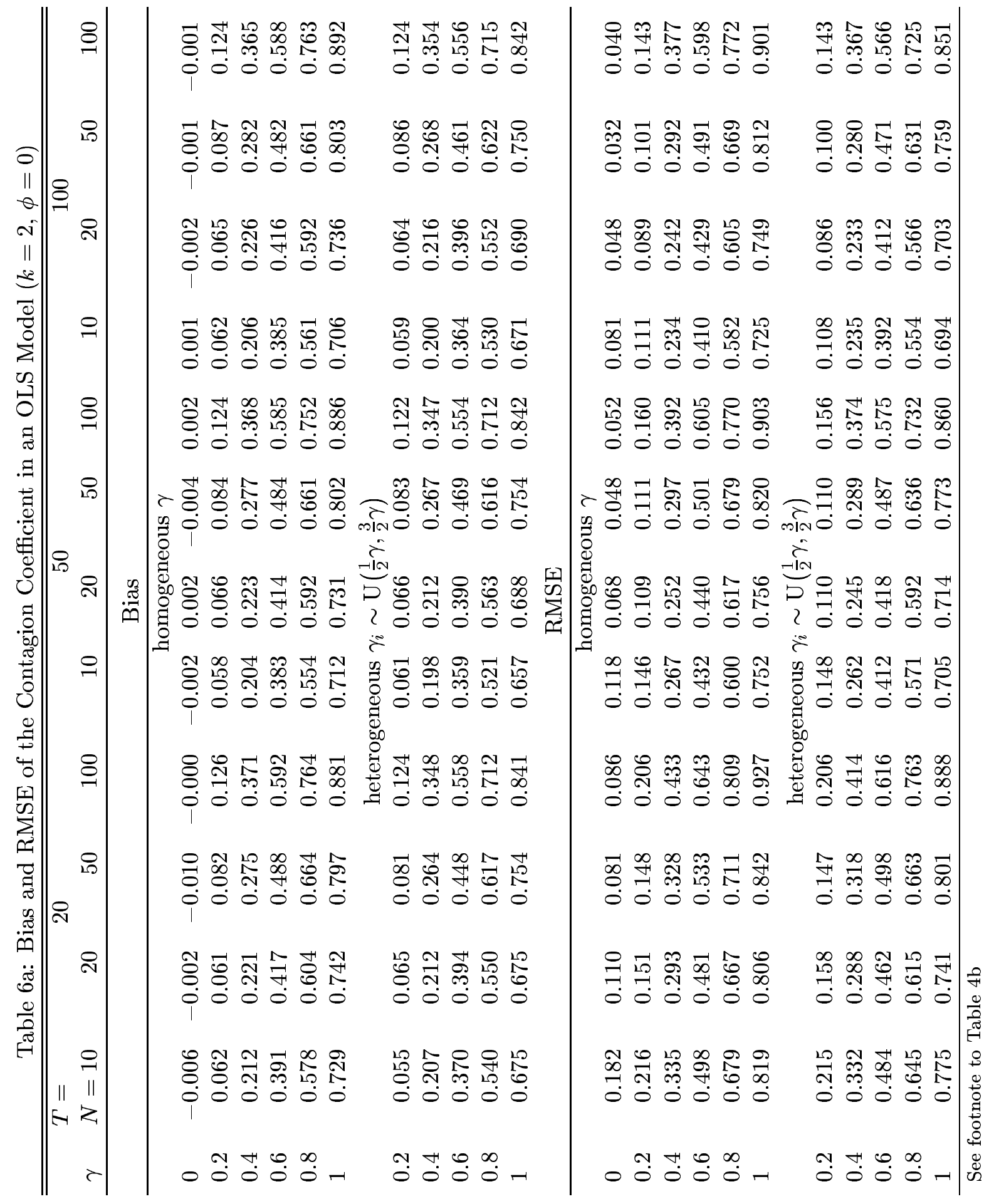




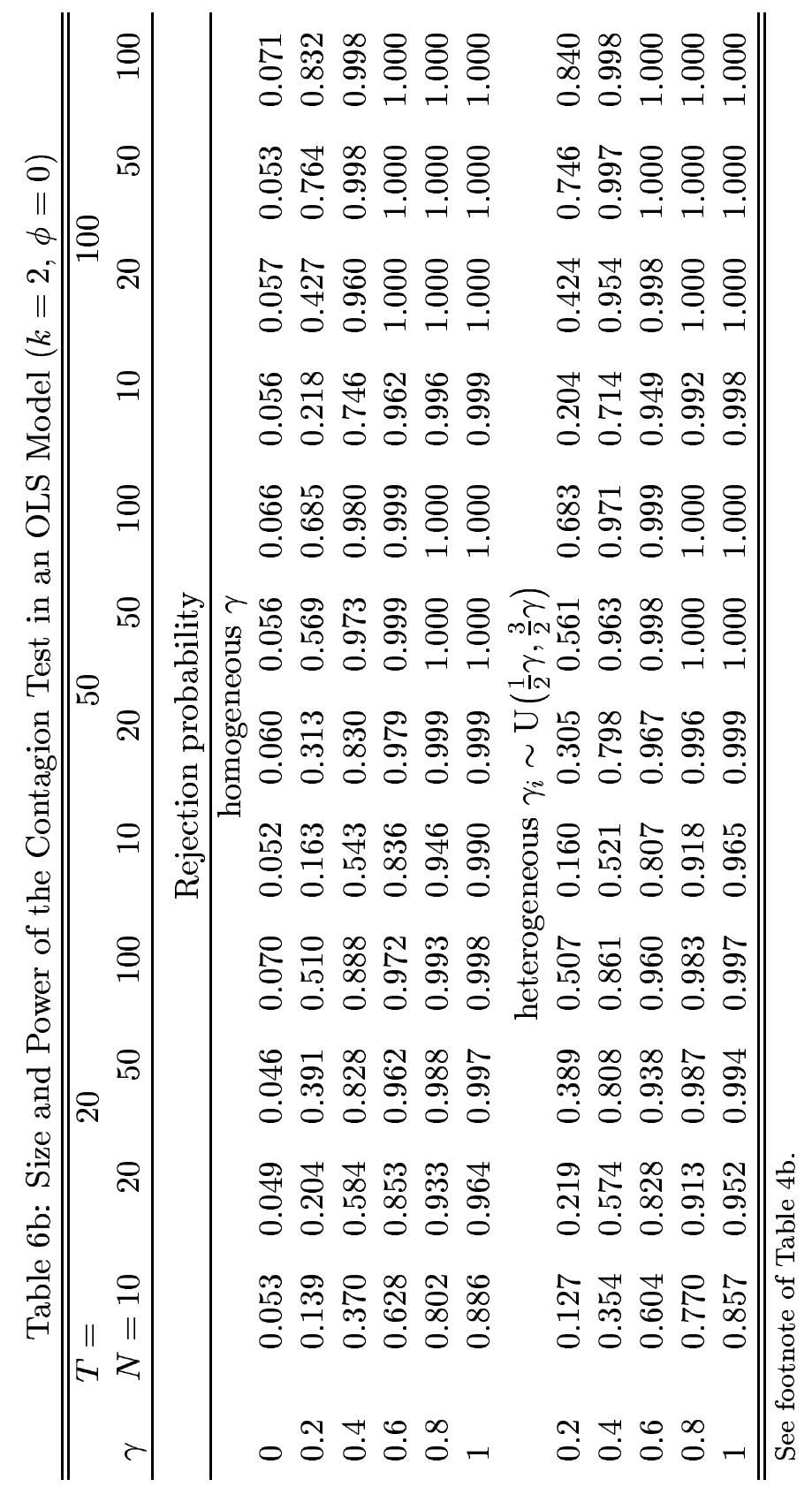




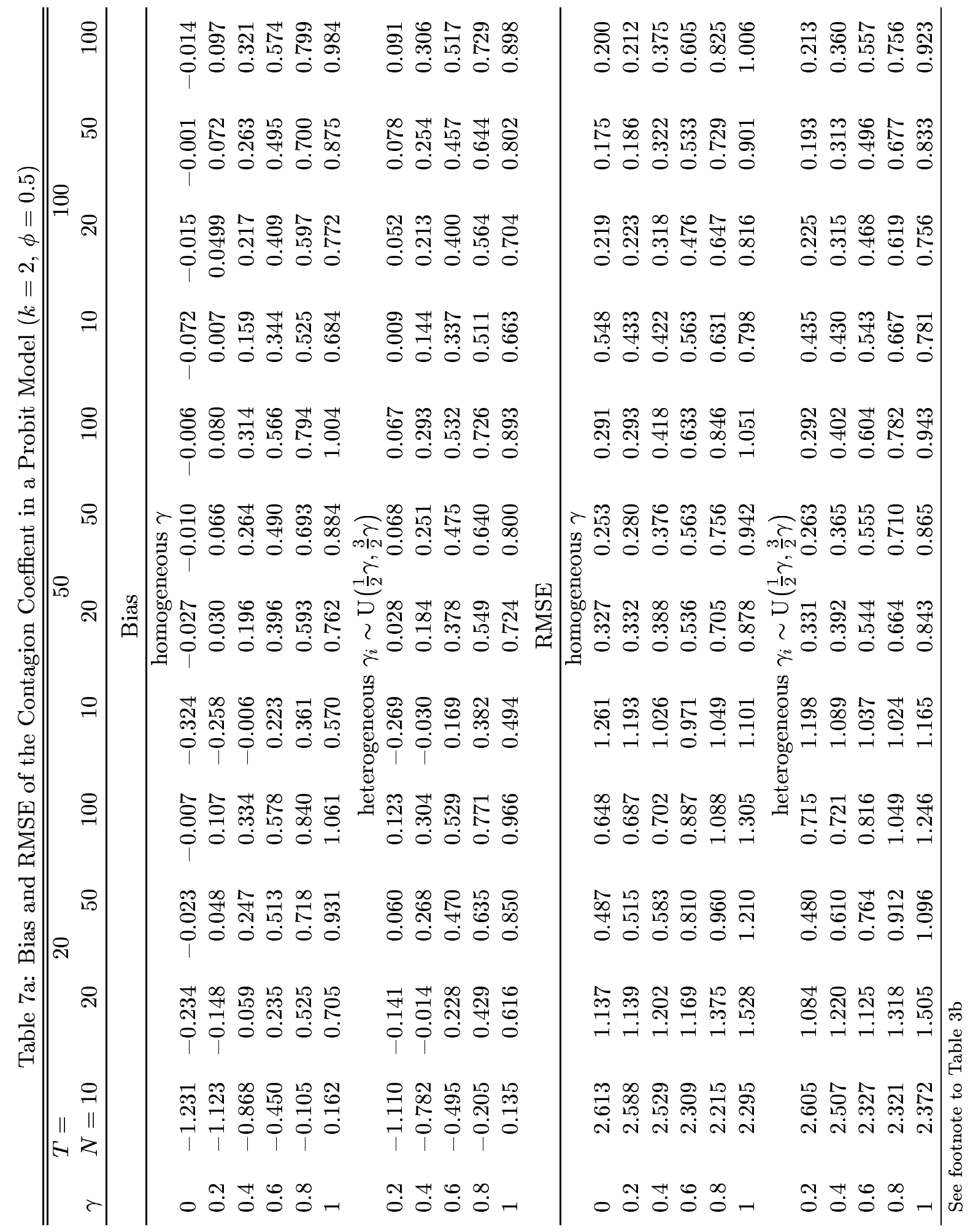




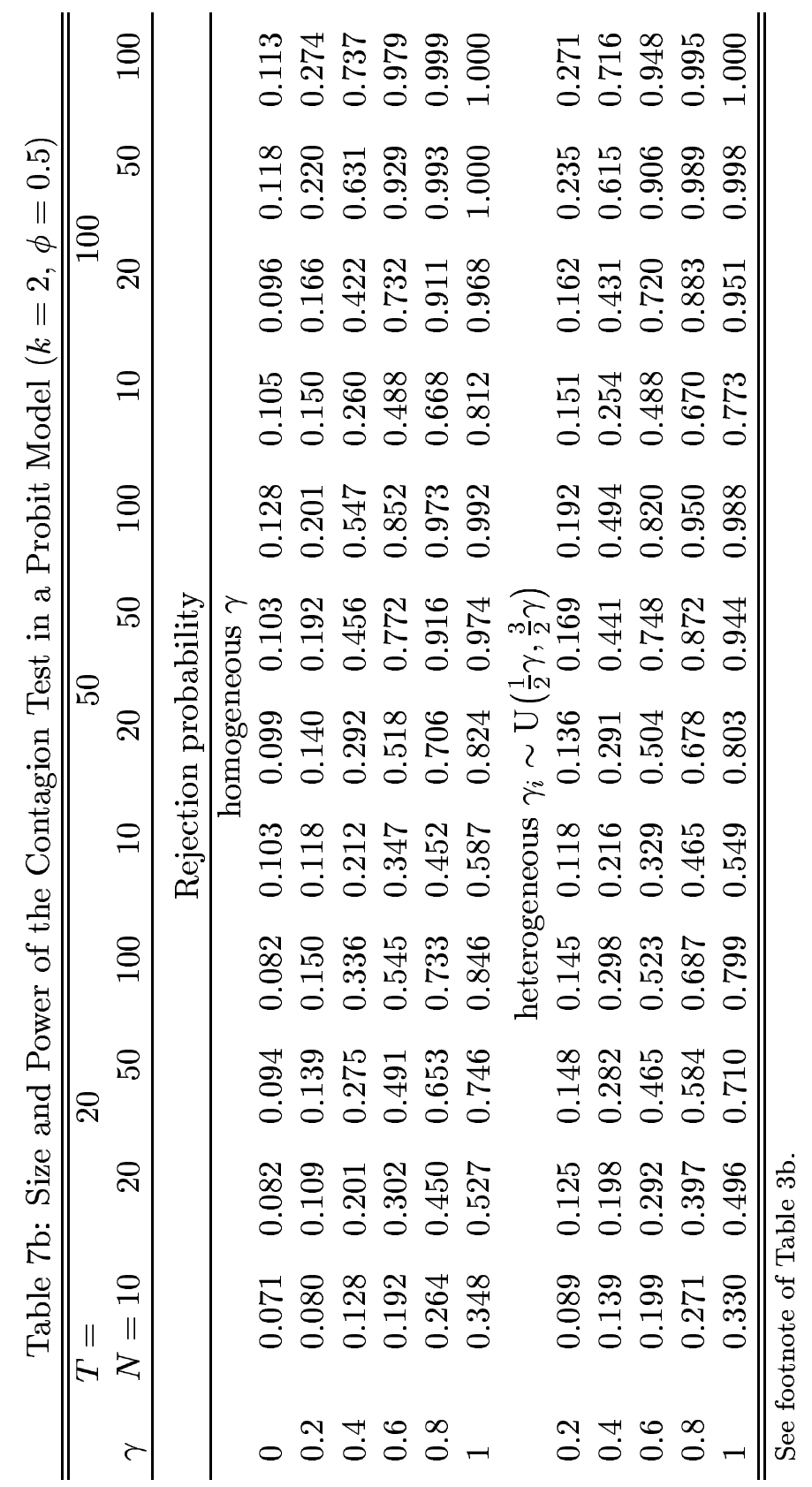




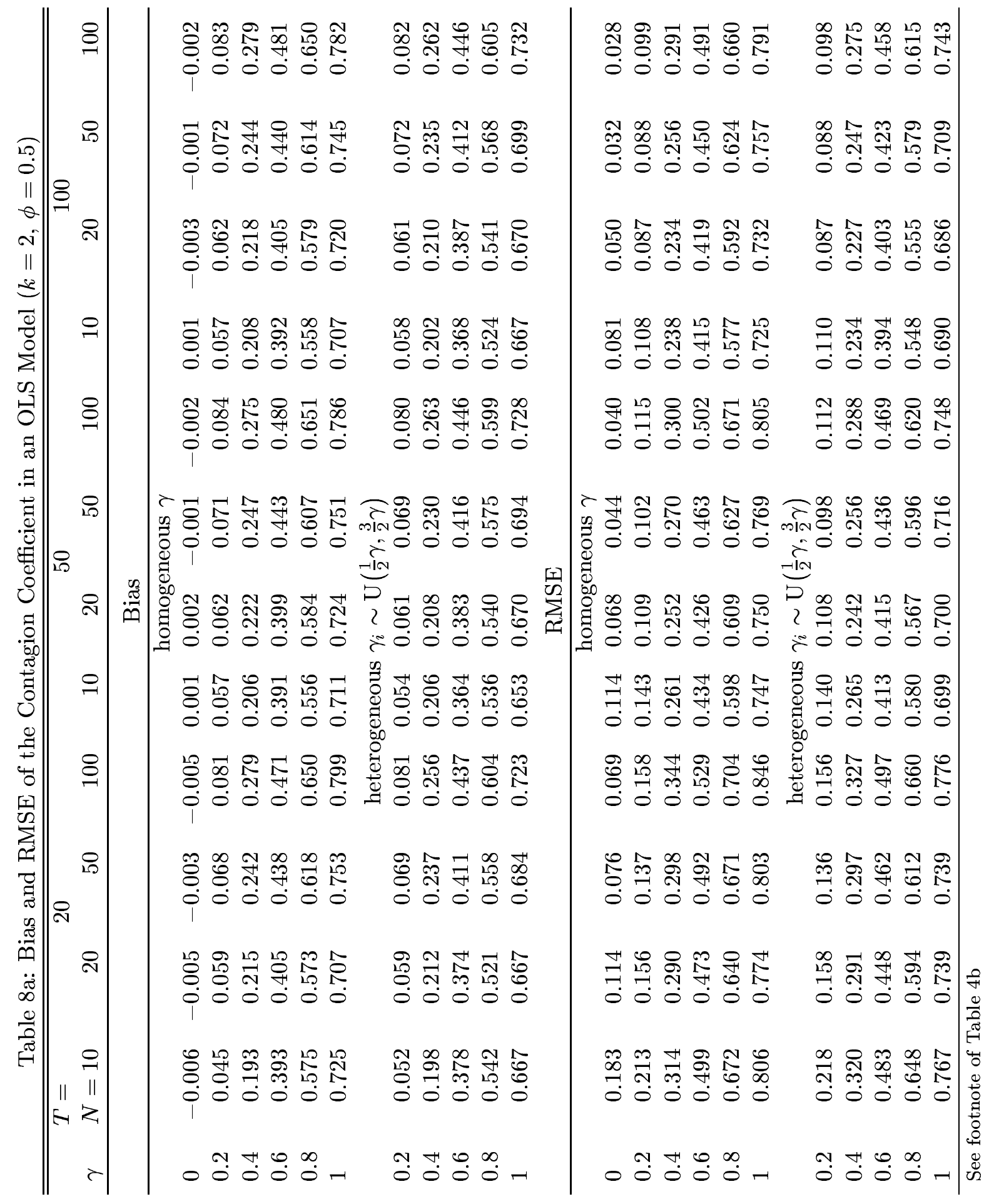




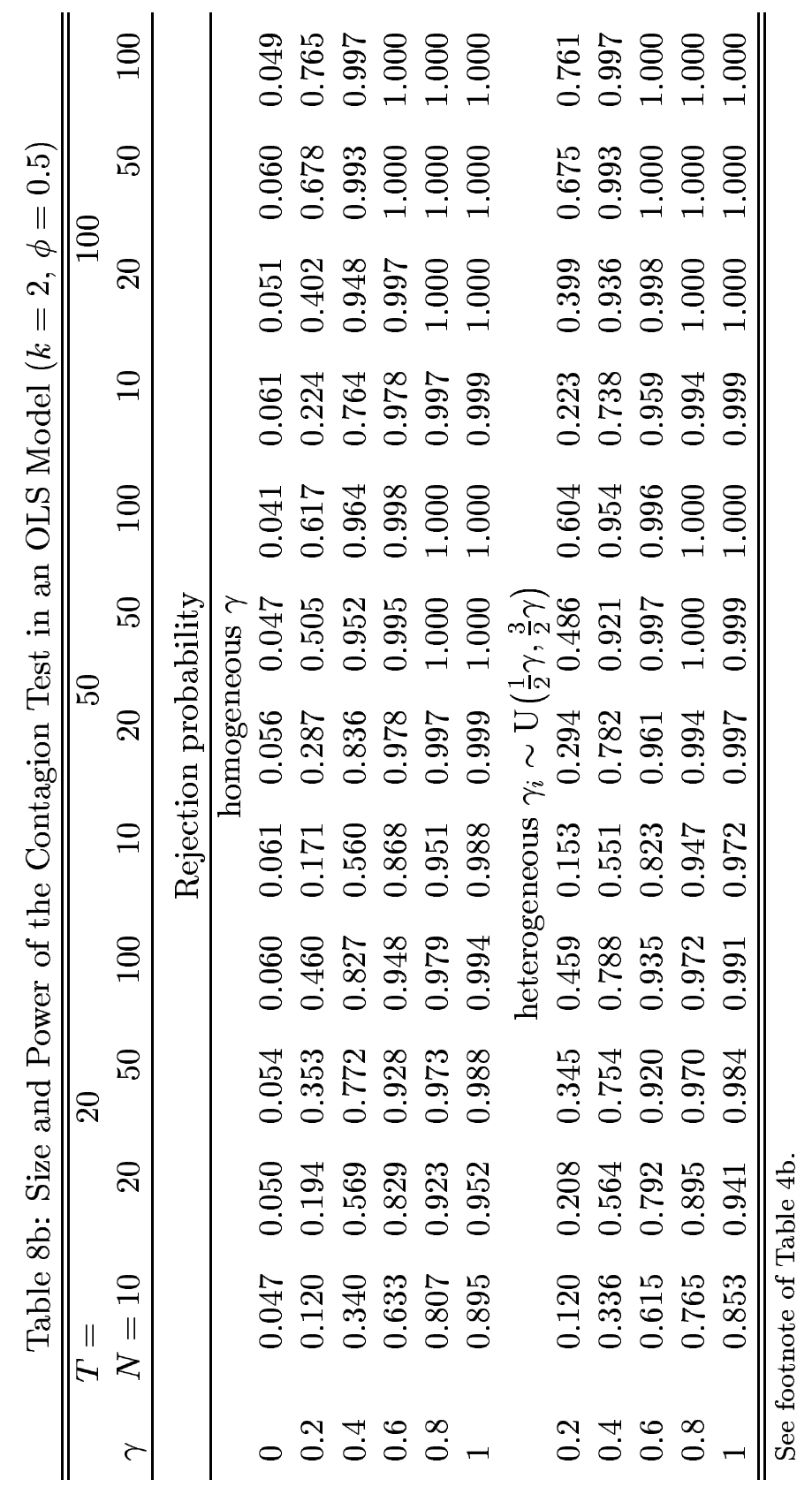


Table 9: Bias, RMSE, Size and Power for the Coefficient of a Spurious Contagion Index (ERW Data)

\begin{tabular}{lrrrrrr}
\hline \hline & \multicolumn{3}{c}{ Probit } \\
\cline { 2 - 7 }$\gamma$ & Bias & RMSE & {$[t>c]$} & Bias & RMSE & {$[t>c]$} \\
\hline \multicolumn{6}{c}{ homogeneous $\gamma_{i}=\gamma$} \\
0 & -0.012 & 0.245 & 0.123 & -0.005 & 0.095 & 0.072 \\
0.2 & 0.074 & 0.245 & 0.215 & 0.079 & 0.128 & 0.297 \\
0.4 & 0.270 & 0.362 & 0.518 & 0.278 & 0.300 & 0.902 \\
0.6 & 0.521 & 0.580 & 0.849 & 0.506 & 0.522 & 0.999 \\
0.8 & 0.773 & 0.818 & 0.981 & 0.713 & 0.725 & 1.000 \\
1 & 0.995 & 1.034 & 0.996 & 0.884 & 0.894 & 1.000 \\
& \multicolumn{6}{c}{ heterogeneous $\gamma_{i} \sim \mathrm{U}\left(\frac{1}{2} \gamma, \frac{3}{2} \gamma\right)$} \\
0.2 & 0.069 & 0.247 & 0.212 & 0.079 & 0.127 & 0.289 \\
0.4 & 0.282 & 0.375 & 0.535 & 0.276 & 0.300 & 0.887 \\
0.6 & 0.528 & 0.588 & 0.858 & 0.492 & 0.510 & 0.996 \\
0.8 & 0.774 & 0.822 & 0.977 & 0.696 & 0.711 & 1.000 \\
1 & 0.998 & 1.042 & 0.996 & 0.863 & 0.875 & 1.000 \\
\hline \hline
\end{tabular}

Data are generated from $y_{i t}^{r}=\boldsymbol{\alpha}^{\prime} \mathbf{x}_{i t}+\varepsilon_{i t}^{r}$, where $\mathbf{x}_{i t}$ are the data of ERW and $\boldsymbol{\alpha}$ the respective probit estimates of the parameters. $\varepsilon_{i t}^{r}=\gamma_{i}^{r} f_{t}^{r}+u_{i t}^{r}$, where $\gamma_{i}^{r} \sim \mathrm{U}\left(\frac{1}{2} \gamma, \frac{3}{2} \gamma\right), f_{t}^{r}, u_{i t}^{r} \sim i i d \mathrm{~N}(0,1)$. The probit estimations use a discretised dependent variable, $\kappa_{i t}^{r}=\mathrm{I}\left(y_{i t}^{r}\right)$, and the OLS estimations the continuous dependent variable, $y_{i t}^{r}$. For the estimations, a spurious contagion dummy was added and the common factor was ignored. The results in the table are for the contagion coefficient, $\hat{\beta}$. Reported are the bias of the coefficient of the contagion coefficient, i. e. $\sum_{r=1}^{R}\left(\hat{\beta}^{(r)}-\beta^{0}\right) / R$, the root mean square error, $\left(\sum_{r=1}^{R}\left(\hat{\beta}^{(r)}-\beta^{0}\right)^{2} / R\right)^{1 / 2}$, where the true value $\beta^{0}=0$ in the DGP and $r=1,2, \ldots, R$ with $R=2000$ is the number of replications. Finally, the one-sided rejection probability denoted $[t>c]$ is reported, which is defined as the probability that the $t$-value is larger than the $95 \%$ critical value (1.645), where the rejection probability under $\gamma=0$ is the size and under $\gamma \neq 0$ the power. 